\title{
COMMISSION 14: ATOMIC AND MOLECULAR DATA ${ }^{1}$ (DONNEES ATOMIQUES ET MOLECULAIRES)
}

\author{
PRESIDENT: F. Rostas
}

VICE-PRESIDENT: P. L. Smith

ORGANIZING COMMITTEE: K. A. Berrington, N. Feautrier, N. Grevesse, S. Johansson, U.G. Jørgensen, W. C. Martin, H. Mason, W. Parkinson, F. Rostas \& W.-Ü L. Tchang-Brillet

In recognition of its special interdisciplinary character, IAU Commission 14 is linked directly to the Executive Committee. The Commission's role is to inform the astronomical community of new developments in the diverse fields of research which involve atoms and molecules. Conversely it endeavors to sensitize the research community active in those fields to the specific needs of astronomy, especially concerning basic data and modeling tools. More generally, Commission 14 tries to foster long term relations and collaborations between the two communities and, when necessary, to alert funding authorities to the specific needs of ground and space based astronomy for specific atomic and molecular data. This report is one of the main contributions of Commission 14 to the information of the astronomical community. Several meetings concerned, at least in part, with the need and availability of atomic and molecular data for astrophysics were also sponsored or co-sponsored. In the last triennium, Commission 14 cosponsored IAU Symposium 194 "Astrochemistry: From Molecular Cloud to Planetary Systems" held in Sogwipo (Korea) from Aug. 23 to 27, 1999 and organized by Commission 34. A Joint Discussion: JD1 on "Atomic and Molecular Data for Astrophysics, New Developments, Case Studies and Future Needs" has been planned for the XXIVth IAU General Assembly in Manchester (Aug. 7-19, 2000) and cosponsored by Commissions 15, 16, 29, 34, 36, 40 and 44. Several other Joint Discussions to be held at the Manchester General Assembly are co-sponsored by this commission.

The present report comprises six sections established by the specialized Working Groups of Commission 14. It is made available on the Commission 14 Website:

http: //www .obspm.fr/IAU14

and its mirror http://cfa-www harvard edu/amp/iau14.

\section{CONTENTS:}

1. ATOMIC SPECTRA AND WAVELENGTH STANDARDS

2. ATOMIC TRANSITION PROBABILITIES

3. COLLISION PROCESSES

4. LINE BROADENING

5. MOLECULAR STRUCTURE AND TRANSITION DATA

6. MOLECULAR REACTIONS ON SOLID SURFACES

\footnotetext{
${ }^{1}$ Committee of the Executive Committee.
} 


\title{
1. WORKING GROUP 1: ATOMIC SPECTRA AND WAVELENGTH STANDARDS
}

\author{
PRESIDENT: S. JOHANSSON
}

\subsection{Energy Level Analyses, Wavelengths and Line Classifications}

The references cited in this section are mostly papers on original laboratory research; compilations and data bases are covered in another section. The references, ordered by atomic number and spectrum, are given in parentheses following the spectral notations. They are designated by the first letter of the first author's last name and a serial number; these designations precede the full citations in the reference list at the end of the report.

Be I (K9), Be II (K8), B II (L2), B III (L1), C I (C2), C IV (T2), O VII (B1), F II (B5), Ne III (L3), Ne IV (B2, C4), Ne V (B3), Mg I, II (P7), Al I (B6), Si VII (K5), Si VIII (K7), S IX (J2), S X (K7), Ar III (K4), Ar V (C1), Ar VII (T1), Sc XFe XV (K6), V I (P1), Cr III (E1), Mn VII (W3), Fe II (B4, B7, N1), Fe VIII (W4), Co I (P3), Co II (P4, P5, P6), Co IX (W5), As III, IV (C3), Kr III (R4), Zr III (R1), Zr IV (R2), Nb III (G1), Mo I (P2), Pd I (E3, M1), Ba I,II (K3), Ce III (W6), Dy III (S1), Ho I (K10), Er III (W7), W II (E2), Re II (W1), Os IV (R6), Pt II (K1), Au II (R5), Hg II (R3), TI II (J1), Pb II (K2), Bi I, II, III (W2)

The references for elements heavier than $\mathrm{Ni}(Z>28)$ are limited to the first three or four spectra only, these data being of interest for solar and stellar spectroscopy. The references of the lighter elements are also incomplete, the selection being limited to those of highest astrophysical interest. The data in a number of references include and/or supersede all or most of the previously available energy-level and/or wavelength data for the indicated spectrum. Such references include those of Be I, Si VII, S IX, Ar III, Ar VII, Cr III, Co I, Co II (P5), Zr III, Zr IV, Nb III, Pd I, Ba I, Ba II, Dy III, Er III, W II, Os IV, and Au II. For elements heavier than $\mathrm{Ga}$, new and unpublished data will be included in the new compilation by Morton (1999) on atomic data for resonance absorption lines.

Current work in high-resolution laboratory spectroscopy of the lowest ionization stages of astrophysical significance is ongoing at Lund (mainly transition elements and rare earth elements), London (third spectra of iron group elements), and NIST (heavy elements, rare earths). The spectroscopy groups at Troitsk (Russia), Amsterdam (NL), Antogonish (CA), Meudon and Orsay (FR) have announced a project on spectroscopy of ions of the 5d elements (The Platinum Group Ion project), in addition to other projects in progress.

\subsection{Wavelength Standards}

The paper by Nave et al. (1997) on accurate Fe II wavelengths in the vacuum-ultraviolet region was discussed in the previous report by W.C. Martin. It has now been published and is mentioned here only for giving complementary information about the reference. A new campaign for very accurate wavelengths of selected lines has been initiated by the current work on the time-variability of the fine structure constant (Webb et al. 1999). The data will certainly be of great interest for spectroscopy of the interstellar medium. The measurements will be carried out at London and Lund, and one paper has already been published for magnesium (Pickering et al. 1998).

\subsection{Larger Compilations, Reviews, Conference Proceedings}

We will mention a few compilations that have appeared during the period 1996-99, as most data are now available in various databases via Internet; some databases are listed in the next section. Kramida and Martin (1997) have compiled the Be I spectrum, and Shirai, Sugar and Musgrove (1999) have submitted a compilation on Ga I-Ga XXXII. Compilations on Highly Ionized Atoms ( $\mathrm{Ti}, \mathrm{V}, \mathrm{Cr}, \mathrm{Mn}, \mathrm{Fe}, \mathrm{Co}, \mathrm{Ni}, \mathrm{Cu}, \mathrm{Kr}, \mathrm{Mo}$ ), on the $\mathrm{Ne}$ I spectrum 
and for all Argon spectra are in preparation in collaborations between NIST, Japan Atomic Energy research Institute and the Institute for Spectroscopy in Troitsk, Russia. At the latter institute, compilations of various ionization stages of neon are completed or in progress. Morton (1999) has submitted a compilation of Atomic Data for Resonance Absorption Lines. II. Wavelengths Longward of the Lyman Limit for Heavy Elements.

A number of papers on atomic spectroscopic data are included in proceedings of the Sixth International Colloquium on Atomic Spectra and Oscillator Strengths for Astrophysical and Laboratory Plasmas, held in Victoria, Canada, August 1998. Invited papers are scheduled for publication (Wiese et al. 1999), and abstracts of contributed papers appear in a publication of the University of Columbia (Tatum 1999). A few papers on astrophysical data needs are included in the proceedings from the first international conference ICAMDATA (International Conference on Atomic and Molecular Data and Their Applications), held at NIST, Gaithersburg, U.S.A., October 1997 (Mohr \& Wiese 1998). Several papers deal with atomic databases. The proceedings of poster papers (Wiese \& Mohr 1998) contain papers about spectroscopic data for astrophysics.

\subsection{Atomic Spectroscopic Data on the Internet}

The URL addresses for a number of World Wide Web sites offering laboratory data of the types covered by Working Groups 1 and 2 are listed below. The italicized names of particular databases or datasets are followed by symbols CL, El, TP in parentheses, indicating types of data:

CL Experimental wavelengths given with energy-level classifications.

EL Experimental values for energy levels.

TP Transition probabilities and/or related quantities (oscillator strengths etc.)

A Weizmann Institute site maintains an updated list of atomic databases and datasets on the Internet: Databases for Atomic and Plasma Physics (Weizmann Inst. of Science, Israel)

http://plasma-gate.weizmann.ac.il/DbfaPP.html

This site has links to most of the databases listed here as well as to a number of others. Instructions are given for e-mail access to data from the Vienna Atomic Line Data-Base (CL, TP) and for ftp downloading of a Spectral Bibliography Database (BIBL), developed and maintained by the Institute of Spectroscopy, Russia.

The NIST Atomic Spectra Database version 2.0, released in March 1999, includes data (Cl, EL, TP) that have been critically compiled either at NIST or by other reliable sources.

http://physics.nist.gov/asd

The database contains $\mathrm{Cl}$, EL, and TP for $\mathrm{H}-\mathrm{Ni}(\mathrm{Z}=1-28)$, with additional EL for $\mathrm{H}-\mathrm{Kr}$ $(\mathrm{Z}=1-36)$, Mo $(\mathrm{Z}=42)$ and the lanthanides $(\mathrm{Z}=57-71)$. The prominent lines from the first five ionization stages are included for $\mathrm{Cu}$ to $\mathrm{Es}(\mathrm{Z}=29-99)$. The database also contains a compilation of "Ground Levels and Ionization Energies for the Neutral Atoms".

Spectral information can be obtained at $C D S$ (Centre de Donnes Astronomiques de Strasbourg, France) and the $A D C$, Astronomical Data Center at NASA Goddard Space Flight Center, U.S.A.

http://cds-web.u-strasbg.fr

http://adc.gsfc.nasa.gov

At CDS, select "Catalogues" and "VI Miscellaneous" (CL, EL, TP) and choose from a list of catalogues including several with extensive atomic spectroscopic data, and use the "Scientific data" and search facility at ADC to get data on CL, EL, and TP. Of similar construction is the WWW Server in NAOJ/ADAC (National Astronomical Observatory, Japan)

http://adac.mtk.nao.ac.jp,

where one selects "Clickable list of the catalogs" and "Miscellaneous Data" (CL, EL, TP) yielding a list including the CDS catalogs (see above). The AMODS (The Atomic Molec- 
ular and Optical Database System) database at Korea Atomic Energy Research Institute contains atomic data (EL,CL,TP) from the CDS and NIST databases on a menu at

http://amods.kaeri.re.kr

By selecting "Databases" at CfA Atomic and Molecular Physics Division (Harvard-Smithsonian Center for Astrophysics)

http://cfa-www . harvard. edu/amp

one gets access to the widely used data on "Kurucz CD-ROM 18" and "Kurucz CD-ROM 23 " (CL, TP) and "Kelly"'s UV/VUV line list (CL). There are also links to other sites.

The Kurucz data can also be found on the European server at

http://www . pmp . uni-hannover .de/projekte/kurucz/sekur.html

Theoretical data (EL,TP) on selected ions of the elements, $\mathrm{Cr}, \mathrm{Mn}, \mathrm{Fe}$, $\mathrm{Co}$ and $\mathrm{Ni}$ are available via ftp from "Atomic Physics Theory" at the University of Amsterdam.

ftp://ftp.wins.uva.nl/pub/orth

The compilation of "Atomic Data for Resonance Absorption Lines" at Herzberg Institute of Astrophysics, Canada, (Morton, 1991) is located at

http://ww.hia.nrc.ca/STAFF/dcm/atomic_data.html

The Atomic Data for Astrophysics (University of Kentucky, U.S.A.) has a database on "Energy Levels, Wavelengths, Transition Probabilities" (CL, TP) and a number of links to other databases and datasets.

http://www.pa.uky.edu/ verner/atom.html

\section{References}

B1 Bartnik, A., et al. 1997, J.Phys.B.:At.Mol.Opt.Phys. 30, 4453

B2 Bastin, T., et al. 1997, J.Opt.Soc.Am. B14, 1319

B3 Bastin, T., et al. 1997, Phys.Scr. 55, 654

B4 Biémont, E., Johansson, S., \& Palmeri, P 1997, Phys.Scr.55, 559

B5 Brown, J.M., Zink, L.R., \& Evenson, K.M. 1998, Phys.Rev.A 57, 2507

B6 Brown, J.M., \& Evenson, K.M. 1999, Phys.Rev.A, in press

B7 Brown, J.M., Körsgen, H., \& Evenson, K.M. 1998, ApJ509, 927

C1 Cavalanti, G.H., et al. 1996, J.Phys B:At.Mol.Opt.Phys 29, 6049

C2 Cheng, E.S., \& Geller, M. 1998, Phys. Scr. 58, 326

C3 Churilov, S.S., \& Joshi, Y.N. 1996 JOSA B13, 11

C4 Churilov, S.S., Kildiyarova, R.R., Bukow, H.H., \& Krenzer, M.J. 1996, Opt. Spectr. 81, 897 .

E1 Ekberg, J.O. 1997, Phys. Scr. 56, 141

E2 Ekberg, J.O., Kling, R., \& Mende, W. 1999, Phys. Scr., (in press)

E3 Engleman, Jr., R., Litzén, U., Lundberg, H., \& Wyart, J.-F. 1998, Phys. Scr. 57, 345

G1 Gayazov, R.R., Ryabtsev, A.N., \& Churilov, S.S. 1998, Phys. Scr. 57, 45

J1 Johansson, S., et al. 1996, ApJ462, 943

J2 Jupén, C., Engström, L. 1997, Phys. Scr. 56, 592

K1 Kalus, G., et al. 1998, ApJ494, 792

K2 Kalus, G., \& Thorne, A.P. 1996, " $5^{\text {th }}$ International Coll. on Atomic Spectra and Oscillator Strengths for Astrophysical and Laboratory Plasmas", Publ. de l'Observatoire de Paris, Meudon, eds. W.-Ü. L. Tchang-Brillet, J.-F. Wyart, C.J. Zeippen, p.4

K3 Karlsson, H., \& Litzén, U. 1999, Phys. Scr., in press

K4 Kaufman, V., \& Whaling W. 1996, J.Res. NIST 101, 691

K5 Kink, I., Engström, L. 1997, Phys. Scr. 56, 31

K6 Kink, I., Tunklev, M., \& Litzén, U. 1997, J.Opt. Soc. Am. B14, 722 
K7 Kink, I., \& Engström, L. 1999, Phys. Scr. 57, 66

K8 Kramida, A.E. 1998, Phys. Scr. 57, 66 .

K9 Kramida, A.E., \& Martin, W.C. 1997, J.Phys.Chem.Ref.Data 26, 1185

K10 Kröger, S., Wyart, J.-F., \& Luc, P. 1997, Phys. Scr. 55, 579

L1 Litzén, U., \& Kling, R. 1998, J.Phys B:At.Mol.Opt.Phys 31, L933

L2 Litzén, U., et al. 1998, Phys Rev. A57, 2477

L3 Livingston et al. 1997, J.Opt.Soc.Am. B14, 522

M1 Mazzoni, M., Joshi, Y.N., \& Wyart, J.-F. 1998, Phys. Scr. 57, 376

Mohr, P., \& Wiese, W.L., Eds., 1998, AIP Conference Proc. 434

Morton, D.C. 1991, ApJS77, 119 .

Morton, D. C. 1999, ApJS, submitted

N1 Nave, G., Johansson, S., \& Thorne, A.P. 1997, J.Opt.Soc.Am. B14, 1035

P1 Palmeri, P., et al., 1997, Phys. Scr. 55, 586

P2 Palmeri, P., \& Wyart, J.-F. 1998, Phys. Scr. 58, 445

P3 Pickering, J.C., \& Thorne, A.P. 1996, ApJS107, 761

P4 Pickering, J.C. 1998, Phys.Scr. 57, 385

P5 Pickering, J.C., Raassen, A.J.J.,Uylings, P.H.M., \& Johansson, S. 1998, ApJS117, 261

P6 Pickering, J.C. 1998, Phys. Scr. 58, 457

P7 Pickering, J.C., Thorne, A.P. \& Webb, J.K. 1998, MNRAS300, 131

R1 Reader, J., \& Acquista, N., 1997, Phys. Scr. 55, 310

R2 Reader, J., \& Acquista, N., 1997, J.Opt.Soc.Am. B14, 1328

R3 Reader, J., \& Sansonetti, C.J. 1999, Phys. Scr. T Ser., (in press)

R4 Reyna-Almandos, J.G., et al. 1996, J.Phys B:At.Mol.Opt.Phys 29, 5643

R5 Rosberg, M., \& Wyart, J.-F. 1997, Phys. Scr. 55, 690

R6 Ryabtsev, A.N., et al 1998, Phys. Scr. 57, 82

Shirai, T., Sugar, J., \& Musgrove, A. 1999, J.Phys. Chem. Ref. Data, submitted

S1 Spector, N., Sugar, J., \& Wyart, J.-F., J.Opt.Soc.Am. B14, 51

Tatum, J., Ed., 1999, Abstracts of Contributed Oral Papers and Poster Papers, $6{ }^{\text {th }}$ Int. Coll. Atom. Spectr. Osc. Str. Astroph. Lab. Plasmas, Univ. of Victoria, B.C., Canada.

T1 Trigueiros, A.G., et al 1997, J.Opt.Soc.Am B14, 2463

T2 Tunklev, M., Engström, L., Jupén, C., \& Kink, I. 1997, Phys. Scr. 55, 707

W1 Wahlgren, G.M., et al. 1997, ApJ475, 380.

W2 Wahlgren, G.M., et al. 1999, ApJ, submitted

W3 Wang, M., et al. 1997, J.Phys B:At.Mol.Opt.Phys 30, 4175

W4 Wang, M., et al. 1997, Phys. Scr. T73, 77

W5 Wang, M., Arnesen, A., Heijkenskjöld, F., \& Hallin, R. 1997, Phys. Scr. 56,609

Webb, J.K., et al 1999, Phys. Rev. Lett. 82, 884

Wiese W.L., \& Mohr, P.J., Eds., 1998, NIST Spec. Publ. 926

Wiese W.L., et al., Eds., 1999, Physica Scripta T series.

W6 Wyart, J.-F., \& Palmeri, P. 1998, Phys. Scr. 58, 368

W7 Wyart, J.-F., Blaise, J., Bidelman, W.P., \& Cowley, C. 1997, Phys. Scr. 56, 446 1998, Phys. Scr. 53, 174 


\section{WORKING GROUP 2: ATOMIC TRANSITION PROBABILITIES}

PRESIDENT: W. L. WIESE

VICE-PRESIDENT: J. R. FUHR

The Data Center on Atomic Transition Probabilities at the National Institute of Standards and Technology (NIST) Gaithersburg, MD 20899, USA is continuing its critical data compilation and bibliographical work. It has contributed all its evaluated transition probability material to a greatly expanded version 2.0 of the NIST atomic spectroscopic database, which has now been installed on the World Wide Web. This database contains about 50,000 transition probabilities with estimated uncertainties and may be accessed via links from the NIST Physics Laboratory WWW homepage at

$$
\text { http://physics.nist.gov }
$$

Details on this and several other atomic spectroscopy databases on the Internet are given in the report of Working Group 1. The comprehensive NIST bibliographical database, which now contains more than 7000 entries, has been updated through May 1999 and is also available at the above cited World Wide Web site. The current compilation work of the NIST atomic transition probabilities data center is centered on the evaluation and tabulation of numerical data for the lighter elements. Work is in progress on hydrogen, helium, lithium, beryllium, boron, fluorine, neon, sodium, magnesium, aluminum, and silicon. The tabulations include allowed (electric dipole) as well as forbidden (mainly magnetic dipole and electric quadruple) lines.

Major tabulations of transition probability data during the period 1996 to the present are the following:

(a) The NIST data center published a 532-page volume of critically evaluated transition probabilities for the three elements carbon, nitrogen and oxygen as Monograph No. 7 of the Journal of Physical and Chemical Reference Data [135]. This volume contains about 12,500 transitions for all 21 spectra of these three elements.

(b) A large database for lines starting from the ground states of many atoms and ions has been put on the World Wide Web by the University of Kentucky "Atomic Data for Astrophysics" server (Verner et al.) [130]. Their listings now contain 890,000 spectral lines, and for about $13 \%$ of these, transition probabilities are included, which are from the Opacity Project.

(c) A review of neutral atom oscillator strengths, published by Doidge [47], in 1995, has been recently updated [48]. This compendium contains oscillator strengths for atomic resonance lines of 65 elements and has been collected mostly for the needs of laboratory atomic absorption spectroscopy.

(d) Morton [76] has prepared a new compilation containing transition probabilities for resonance lines of heavier elements $(\mathrm{Ge}-\mathrm{Bi}$, plus limited data for $\mathrm{Tc}, \mathrm{Th}$ and $\mathrm{U})$. These data are scheduled to be published in the Astrophysical Journal, Supplement Series, as well as on a website.

The following theoretical and experimental projects have been especially active and have contributed many new numerical data during the last three years:

(a) Large amounts of data have been calculated as part of the Opacity Project and its successor, the Iron Project. In particular, very extensive calculations of transition probabilities for various ions of iron have been undertaken $[8,9,83,84]$.

(b) Raassen and co-workers [102-106, 127] have calculated large quantities of oscillator strengths for ionized atoms of the iron group elements by using the "orthogonal operator" approach. Comparisons with experiments indicate that the results are quite accurate. The data are available on the World Wide Web at

http://www.wins. uva.nl/research/atom/levels/levtext.html 
(c) Lawler and co-workers $[5,10,11,37,39,77-79,88,132-134]$ have measured numerous transition probabilities of neutral and singly ionized atoms of the Fe-group as well as of several other heavier elements by a combined branching ratio-lifetime technique.

Finally, it is of interest to note that a number of informative review articles on the status and accuracy of oscillator strength data were given at the 6th International Colloquium on Atomic Spectra and Oscillator Strengths for Astrophysical and Laboratory Plasmas (ASOS 6), the proceedings of which are in preparation (see Wiese and Morton) [136].

The remaining part of this report is a bibliography of selected recent literature references, which contain new transition probability data of astrophysical interest produced during the last three-year period. Thus, this new selected bibliography continues where the last working group report left off. As in the previous reports, the bibliographical material is ordered with respect to element and stage of ionization. Table 1 provides an overview of the bibliographical data by spectrum. The references are identified by a running number, which refers to the general reference list at the end of this report. In the general reference list the literature is ordered alphabetically according to the first author, and each reference contains one or more code letters indicating the method applied by the authors. These code letters are defined as follows:

THEORETICAL METHODS:

$\mathrm{Q}$ - quantum mechanical calculations

\section{EXPERIMENTAL METHODS:}

E - measurements in emission (arc, hollow cathode, etc.).

A - measurements in absorption (absorption tube, etc.).

L - lifetime measurements (laser induced fluorescence, beam-laser and beam-foil spectroscopy, etc.).

M - miscellaneous experimental methods (for example, Stark effect, astrophysical measurements, etc.).

\section{OTHER:}

$R$ - relative values only

$\mathrm{F}$ - forbidden transitions (not electric dipole)

CP - data compilations

CM - comments 
Table 1. Important Literature References

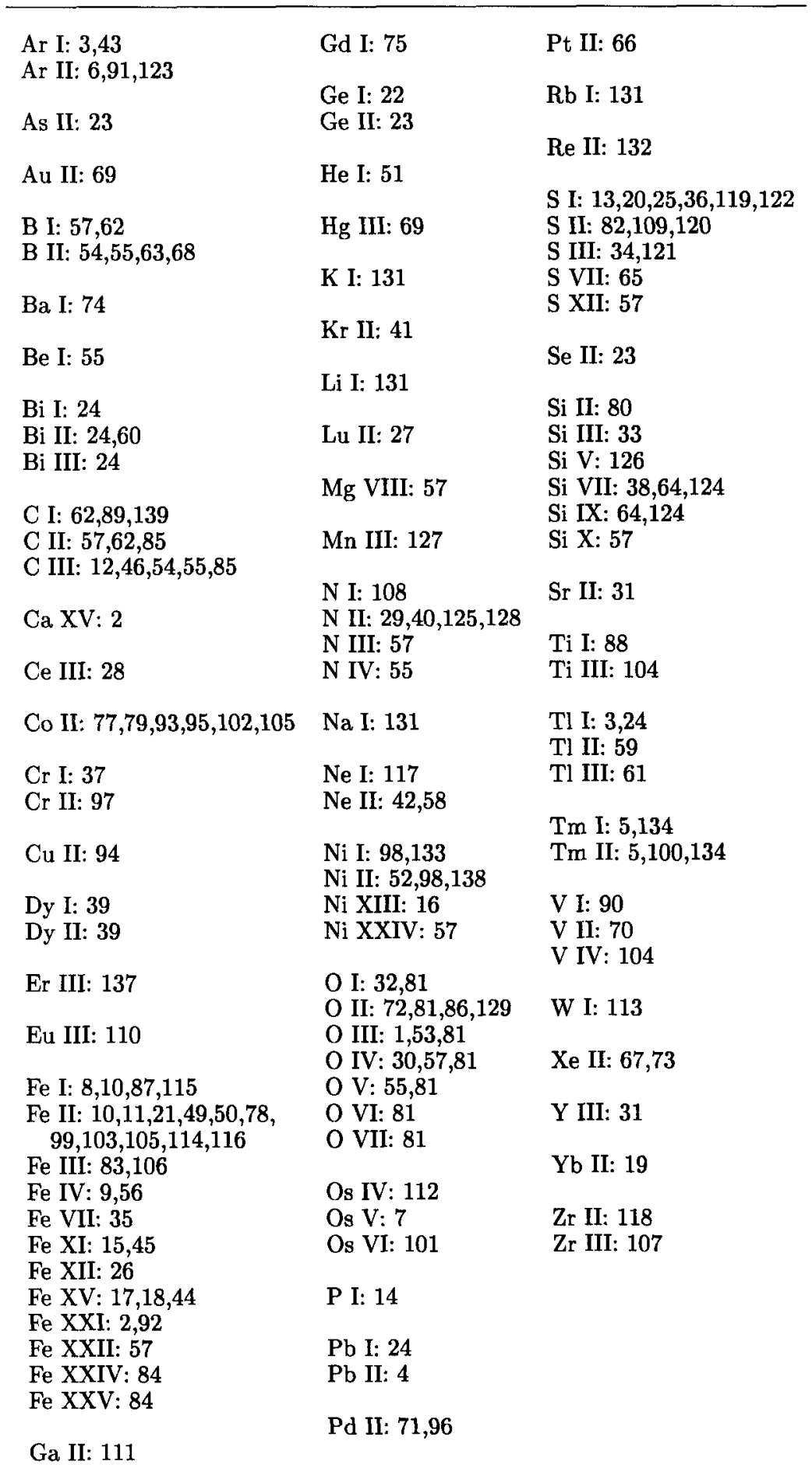




\section{References}

1. Aggarwal, K. M., Hibbert, A., Keenan, F. P.: Astrophys. J., Suppl. Ser. 108, 393 (1997) Q

2. Aggarwal, K. M., Hibbert, A., Keenan, F. P., Norrington, P. H.: Astrophys. J., Suppl. Ser. 108, 575 (1997) Q

3. Alonso-Medina, A.: J. Quant. Spectrosc. Radiat. Transfer 56, 557 (1996) E

4. Alonso-Medina, A.: Phys. Scr. 55, 49 (1997) E

5. Anderson, H. M., Den Hartog, E. A., Lawler, J. E.: J. Opt. Soc. Am. B 13, 2382 (1996) $\mathrm{L}$

6. Aparicio, J. A., Gigosos, M. A., Mar, S.: J. Phys. B 30, 3141 (1997) E

7. Azarov, V. I., Raassen, A. J. J., Joshi, Y. N., Uylings, P. H. M., Ryabtsev, A. N.: Phys. Scr. 56, 325 (1997) Q

8. Bautista, M. A.: Astron. Astrophys., Suppl. Ser. 122, 167 (1997) Q

9. Bautista, M. A., Pradhan, A. K.: Astron. Astrophys., Suppl. Ser. 126, 365 (1997) Q

10. Bergeson, S. D., Mullman, K. L., Lawler, J. E.: Astrophys. J. 464, 1050 (1996) A, AR

11. Bergeson, S. D., Mullman, K. L., Wickliffe, M. E., Lawler, J. E., Litzen, U., Johansson, S.: Astrophys. J. 464, 1044 (1996) E

12. Berrington, K., Pelan, J., Quigley, L.: Phys. Scr. 57, 549 (1998) Q

13. Berzinsh, U., Caiyan, Luo, Zerne, R., Svanberg, S., Biemont, E.: Phys. Rev. A 55, 1836 (1997) L, Q

14. Berzinsh, U., Svanberg, S., Biemont, E.: Astron. Astrophys. 326, 412 (1997) L, Q

15. Bhatia, A. K., Doschek, G. A.: At. Data Nucl. Data Tables 64, 183 (1996) Q, QF

16. Bhatia, A. K., Doschek, G. A.: At. Data Nucl. Data Tables 68, 49 (1998) Q, QF

17. Bhatia, A. K., Mason, H. E.: At. Data Nucl. Data Tables 66, 119 (1997) Q

18. Bhatia, A. K., Mason, H. E., Blancard, C.: At. Data Nucl. Data Tables 66, 83 (1997) $\mathrm{Q}, \mathrm{QF}$

19. Biemont, E., Dutrieux, J.-F., Martin, I., Quinet, P.: J. Phys. B 31, 3321 (1998) Q

20. Biemont, E., Garnir, H. P., Federman, S. R., Li, Z. S., Svanberg, S.: Astrophys. J. 502, 1010 (1998) L, Q

21. Biemont, E., Johansson, S., Palmeri, P.: Phys. Scr. 55, 559 (1997) Q

22. Biemont, E., Lynga, C., Li, Z. S., Svanberg, S., Garnir, H. P., Doidge, P. S.: Mon. Not. R. Astron. Soc. 303, 721 (1999) E, L, Q

23. Biemont, E., Morton, D. C., Quinet, P.: Mon. Not. R. Astron. Soc. 297, 713 (1998) Q

24. Biemont, E., Quinet, P.: Phys. Scr. 54, 36 (1996) QF

25. Biemont, E., Storey, P. J., Zeippen, C. J.: Astron. Astrophys. 309, 991 (1996) Q

26. Binello, A. M., Mason, H. E., Storey, P. J.: Astron. Astrophys., Suppl. Ser. 127, 545 (1998) Q

27. Bord, D. J., Cowley, C. R., Mirijanian, D.: Sol. Phys. 178, 221 (1998) Q

28. Bord, D. J., Cowley, C. R., Norquist, P. L.: Mon. Not. R. Astron. Soc. 284, 869 (1997) Q

29. Brage, T., Hibbert, A., Leckrone, D. S.: Astrophys. J. 478, 423 (1997) Q

30. Brage, T., Judge, P. G., Brekke, P.: Astrophys. J. 464, 1030 (1996) Q

31. Brage, T., Wahlgren, G. M., Johansson, S. G., Leckrone, D. S., Proffitt, C. R.: Astrophys. J. 496, 1051 (1998) Q

32. Bridges, J. M., Wiese, W. L.: Phys. Rev. A 57, 4960 (1998) E

33. Callegari, F., Trigueiros, A. G.: Astrophys. J., Suppl. Ser. 119, 181 (1998) Q 
34. Charro, E., Martin, I.: Astron. Astrophys. 343, 634 (1999) Q

35. Charro, E., Martin, I.: Astrophys. J. 513, 997 (1999) Q

36. Chen, Z., Msezane, A. Z.: J. Phys. B 30, 3873 (1997) Q

37. Cooper, J. C., Gibson, N. D., Lawler, J. E.: J. Quant. Spectrosc. Radiat. Transfer 58, 85 (1997) L

38. Coutinho, L. H., Trigueiros, A. G.: Astrophys. J., Suppl. Ser. 115, 315 (1998) Q

39. Curry, J. J., Den Hartog, E. A., Lawler, J. E.: J. Opt. Soc. Am. B 14, 2788 (1997) L

40. Curry, J. J., Gibson, N. D., Lawler, J. E.: Astron. Astrophys. 321, 1021 (1997) ER

41. Das, M. B.: J. Quant. Spectrosc. Radiat. Transfer 57, 237 (1997) L

42. Das, M. B.: Z. Phys. D 39, 257 (1997) L

43. de Regt, J. M., Tas, R. D., van der Mullen, J. A. M., van der Sijde, B., Schram, D. C.: J. Quant. Spectrosc. Radiat. Transfer 56, 67 (1996) E

44. Deb, N. C., Msezane, A. Z.: J. Phys. B 31, L281 (1998) Q

45. Deb, N. C., Tayal, S. S.: At. Data Nucl. Data Tables 69, 161 (1998) Q

46. Doerfert, J., Träbert, E., Wolf, A., Schwalm, D., Uwira, O.: Phys. Rev. Lett. 78, 4355 (1997) L

47. Doidge, P. S.: Spectrochim. Acta, Part B 50, 209 (1995); 50, 1421 (1995); 51, 375 (1996) CP

48. Doidge, P.S.: in Proceed. 6th Internat. Colloq. At. Spectra Osc. Str., to be published in Phys. Scr., T Series, 1999 CP

49. Donnelly, M. P., Hibbert, A.: Mon. Not. R. Astron. Soc. 301, 809 (1998) Q

50. Donnelly, M. P., Hibbert, A.: Mon. Not. R. Astron. Soc. 302, 413 (1999) Q

51. Drake, G. W. F.: Atomic, Molecular, and Optical Physics Handbook, 154-171 (1996) Q

52. Ferrero, F. S., Manrique, J., Zwegers, M., Campos, J.: J. Phys. B 30, 893 (1997) E, Q

53. Fleming, J., Brage, T.: J. Phys. B 30, 1385 (1997) Q

54. Froese Fischer, C., Gaigalas, G.: Phys. Scr. 56, 436 (1997) Q

55. Froese Fischer, C., Gaigalas, G., Godefroid, M.: J. Phys. B 30, 3333 (1997) Q

56. Froese Fischer, C., Rubin, R. H.: J. Phys. B 31, 1657 (1998) QF

57. Galavis, M. E., Mendoza, C., Zeippen, C. J.: Astron. Astrophys., Suppl. Ser. 131, 499 (1998) Q, QF

58. Griesmann, U., Musielok, J., Wiese, W. L.: J. Opt. Soc. Am. B 14, 2204 (1997) E, ER

59. Henderson, M., Curtis, L. J.: J. Phys. B 29, L629 (1996) L

60. Henderson, M., Curtis, L. J., Ellis, D. G., Irving, R. E., Wahlgren, G. M.: Astrophys. J. 473, 565 (1996) L, Q

61. Henderson, M., Curtis, L. J., Matulioniene, R., Ellis, D. G., Theodosiou, C. E.: Phys. Rev. A 56, 1872 (1997) L, Q

62. Jönsson, P., Froese Fischer, C., Godefroid, M. R.: J. Phys. B 29, 2393 (1996) Q

63. Jönsson, P., Litzen, U., Zethson, T., Kling, R., Launay, F.: Astrophys. J. 499, L107 (1998) Q

64. Kink, I., Jupen, C., Engstroem, L., Feldman, U., Laming, J. M., Schuehle, U.: Astrophys. J. 487, 956 (1997) Q

65. Kirm, M., Bengtsson, P., Engström, L.: Phys. Scr. 54, 167 (1996) L

66. Larsson, J., Zerne, R., Lundberg, H.: J. Phys. B 29, 1895 (1996) L

67. Lidberg, J., Al-Khalili, A., Cowan, R. D., Norlin, L.-O., Royen, P., Mannervik, S.: Phys. Rev. A 56, 2692 (1997) LF 
68. Litzen, U., Zethson, T., Jönsson, P., Kasten, J., Kling, R., Launay, F.: Phys. Rev. A 57, 2477 (1998) Q

69. Loginov, A. V., Tuchkin, V. I.: Opt. Spectrosc. 85, 1 (1998) Q

70. Luke, T. M.: J. Phys. B 30, 4223 (1997) Q

71. Lundberg, H., Johansson, S. G., Larsson, J., Leckrone, D. S., Litzen, U., Svanberg, S., Wahlgren, G. M., Zerne, R.: Astrophys. J. 469, 388 (1996) E, Q

72. Marketos, P., Nandi, T.: Z. Phys. D 42, 237 (1997) Q

73. Martin, I., Hernando, C., Lavin, C., Velasco, A. M.: J. Quant. Spectrosc. Radiat. Transfer 62, 71 (1999) Q

74. Matsuo, Y., Nakajima, T., Kobayashi, T., Takami, M.: Phys. Rev. A 59, 2071 (1999) L

75. Miyabe, M., Wakaida, I., Arisawa, T.: Z. Phys. D 39, 181 (1997) L, M

76. Morton, D. C.: to be published in Astrophys. J., Suppl. Ser., 1999. CP

77. Mullman, K. L., Cooper, J. C., Lawler, J. E.: Astrophys. J. 495, 503 (1998) E, L

78. Mullman, K. L., Lawler, J. E.: Astron. Astrophys., Suppl. Ser. 122, 157 (1997) A

79. Mullman, K. L., Lawler, J. E., Zsargo, J., Federman, S. R.: Astrophys. J. 500, 1064 (1998) A

80. Nahar, S. N.: At. Data Nucl. Data Tables 68, 183 (1998) Q

81. Nahar, S. N.: Phys. Rev. A 58, 3766 (1998) Q

82. Nahar, S. N.: Phys. Scr. 55, 200 (1997) Q

83. Nahar, S. N., Pradhan, A. K.: Astron. Astrophys., Suppl. Ser. 119, 509 (1996) Q, QF

84. Nahar, S. N., Pradhan, A. K.: Astron. Astrophys., Suppl. Ser. 135, 347 (1999) Q

85. Nandi, T., Bhattacharya, N., Kurup, M. B., Prasad, K. G.: Phys. Scr. 54, 179 (1996) L

86. Nandi, T., Marketos, P., Bhattacharya, N., Mitra, S. K.: J. Phys. B 32, 769 (1999) L

87. Nave, G., Johansson, S., Learner, R. C. M., Thorne, A. P., Brault, J. W.: Astrophys. J., Suppl. Ser 94, 221 (1994) CP

88. Nitz, D. E., Wickliffe, M. E., Lawler, J. E.: Astrophys. J., Suppl. Ser. 117, 313 (1998) E

89. O'Brian, T. R., Lawler, J. E.: J. Quant. Spectrosc. Radiat. Transfer 57, 309 (1997) L

90. Palmeri, P., Biemont, E., Quinet, P., Dembczynski, J., Szawiola, G., Kurucz, R. L.: Phys. Scr. 55, 586 (1997) Q

91. Pellerin, S., Musiol, K., Dzierzega, K., Chapelle, J.: J. Quant. Spectrosc. Radiat. Transfer 57, 359 (1997) E

92. Phillips, K. J. H., Bhatia, A. K., Mason, H. E., Zarro, D. M.: Astrophys. J. 466, 549 (1996) Q, QF

93. Pickering, J. C.: Phys. Scr. 58, 457 (1998) Q

94. Pinnington, E. H., Rieger, G., Kernahan, J. A., Biemont, E.: Can. J. Phys. 75, 1 (1997) L, Q

95. Quinet, P.: Astron. Astrophys., Suppl. Ser. 129, 147 (1998) QF

96. Quinet, P.: Phys. Scr. 54, 483 (1996) Q

97. Quinet, P.: Phys. Scr. 55, 41 (1997) QF

98. Quinet, P., Le Dourneuf, M.: Astron. Astrophys., Suppl. Ser. 119, 99 (1996) QF

99. Quinet, P., Le Dourneuf, M., Zeippen, C. J.: Astron. Astrophys., Suppl. Ser. 120, 361 (1996) QF

100. Quinet, P., Palmeri, P., Biemont, E.: J. Quant. Spectrosc. Radiat. Transfer 62, 625 (1999) Q 
101. Raassen, A. J. J., Azarov, V. I., Uylings, P. H. M., Joshi, Y. N., Tchang-Brillet, L., Ryabtsev, A. N.: Phys. Scr. 54, 56 (1996) Q

102. Raassen, A. J. J., Pickering, J. C., Uylings, P. H. M.: Astron. Astrophys., Suppl. Ser. 130, 541 (1998) Q

103. Raassen, A. J. J., Uylings, P. H. M.: Astron. Astrophys. 340, 300 (1998) Q

104. Raassen, A. J. J., Uylings, P. H. M.: Astron. Astrophys., Suppl. Ser. 123, 147 (1997) $\mathrm{Q}, \mathrm{QF}$

105. Raassen, A. J. J., Uylings, P. H. M.: J. Phys. B 31, 3137 (1998) Q

106. Raassen, A. J. J., Uylings, P. H. M.: Phys. Scr. T65, 84 (1996) Q

107. Reader, J., Acquista, N.: Phys. Scr. 55, 310 (1997) Q

108. Robinson, D. J. R., Hibbert, A.: J. Phys. B 30, 4813 (1997) Q

109. Rojas, J. A. M., Ortiz, M., Campos, J.: J. Quant. Spectrosc. Radiat. Transfer 62, 433 (1999) E

110. Ryabchikova, T., Piskunov, N., Savanov, I., Kupka, F., Malanushenko, V.: Astron. Astrophys. 343, 229 (1999) M

111. Ryabchikova, T. A., Smirnov, Yu. M.: Astron. Rep. 38, 70 (1994) E

112. Ryabtsev, A. N., Raassen, A. J., Tchang-Brillet, W.-Ul., Joshi, Y. N., Uylings, P. H. M., Azarov, V. I.: Phys. Scr. 57, 82 (1998) Q

113. Schnabel, R., Kock, M.: Z. Phys. D 41, 31 (1997) L

114. Schnabel, R., Kock, M., Holweger, H.: Astron. Astrophys. 342, 610 (1999) L

115. Schoenfeld, W. G., Chang, E. S., Geller, M., Johansson, S., Nave, G., Sauval, A. J., Grevesse, N.: Astron. Astrophys. 301, 593 (1995) M, Q

116. Schultz-Johanning, M., Schnabel, R., Kock, M.: Eur. Phys. J. D 5, 341 (1999) L

117. Seaton, M. J.: J. Phys. B 31, 5315 (1998) Q

118. Sikstroem, C. M., Lundberg, H., Wahlgren, G. M., Li, Z. S., Lynga, C., Johansson, S., Leckrone, D. S.: Astron. Astrophys. 343, 297 (1999) E, L

119. Tayal, S. S.: Astrophys. J. 497, 493 (1998) Q

120. Tayal, S. S.: Astrophys. J., Suppl. Ser. 111, 459 (1997) Q

121. Tayal, S. S.: At. Data Nucl. Data Tables 67, 331 (1997) Q

122. Tayal, S. S.: J. Phys. B 30, L551 (1997) Q

123. Tayal, S. S., Henry, R. J. W.: J. Phys. B 29, 3443 (1996) Q

124. Träbert, E., Wolf, A., Pinnington, E. H., Linkemann, J., Knystautas, E. J., Curtis, A., Bhattacharya, N., Berry, H. G.: Can. J. Phys. 76, 899 (1998) LF

125. Träbert, E., Wolf, A., Pinnington, E. H., Linkemann, J., Knystautas, E. J., Curtis, A., Bhattacharya, N., Berry, H. G.: Phys. Rev. A 58, 4449 (1998) L

126. Trigueiros, A. G., Jupen, C.: J. Quant. Spectrosc. Radiat. Transfer 56, 713 (1996) Q

127. Uylings, P. H. M., Raassen, A. J. J.: Astron. Astrophys., Suppl. Ser. 125, 539 (1997) Q, QF

128. Vaeck, N., Fleming, J., Bell, K. L., Hibbert, A., Godefroid, M. R.: Phys. Scr. 56, 603 (1997) Q

129. Veres, G., Wiese, W. L.: Phys. Rev. A 54, 1999 (1996) E

130. Verner, D.A.: http://www.pa.uky.edu/ verner/atom.html. CP

131. Volz, U., Schmoranzer, H.: Phys. Scr. T65, 48 (1996) L

132. Wahlgren, G. M., Johansson, S. G., Litzen, U., Gibson, N. D., Cooper, J. C., Lawler, J. E., Leckrone, D. S., Engleman, Jr., R.: Astrophys. J. 475, 380 (1997) E, L

133. Wickliffe, M. E., Lawler, J. E.: Astrophys. J., Suppl. Ser 110, 163 (1997) E

134. Wickliffe, M. E., Lawler, J. E.: J. Opt. Soc. Am. B 14, 737 (1997) E 
135. Wiese, W. L., Fuhr, J. R., Deters, T. M.: J. Phys. Chem. Ref. Data, Monograph No. 7, 532 pp. (1996) CP, CPF

136. Wiese, W. L., Morton, D. C.: Eds., Proceed. 6th Internat. Colloq. At. Spectra Osc. Str., to be published in Phys. Scr., T Series, 1999 CM, M

137. Wyart, J.-F., Blaise, J., Bidelman, W. P., Cowley, C. R.: Phys. Scr. 56, 446 (1997) $\mathrm{Q}$

138. Zsargo, J., Federman, S. R.: Astrophys. J. 498, 256 (1998) MR

139. Zsargo, J., Federman, S. R., Cardelli, J. A.: Astrophys. J. 484, 820 (1997) M

\title{
3. WORKING GROUP 3: COLLISION PROCESSES
}

\author{
PRESIDENT: D. R. SCHULTZ
}

VICE-PRESIDENT: P. C. STANCIL

Within the broad classification "atomic and molecular collision processes" that are of active or anticipated interest in astrophysics, several hundred published works have appeared since the last summary report of this working group in 1996. Owing to the size and scope of this body of work, rather than seeking to comprehensively review it, here we attempt to identify works of particular importance and compilations that make use of the data especially efficient. Also, since a significant overlap between the atomic and molecular collision processes that are relevant to fusion energy development and those relevant to astrophysics exists, a majority of the literature references of interest can be found using the bibliographic search engine at the ORNL Controlled Fusion Atomic Data Center (CFADC 1999) which currently covers the period 1978 to present. Categorized bibliographies based largely on this database dating from 1969 to 1998 have also been published (CIAMDA 1998). For ease of organization, here we sub-divide "collision processes" using the following scheme: (1) electron impact of atoms and ions, (2) electron impact of molecules, (3) ion-atom and atom-atom collisions, (4) ion-molecule and atom-molecule collisions, and (5) reactive scattering and chemistry. Each of these sub-classes contains the pertinent range of collisions processes (e.g. elastic scattering, excitation, ionization, recombination, particle interchange, etc.).

\subsection{Electron Impact of Atoms and Ions}

Electron collisions with atoms and ions constitute the major excitation mechanism in the majority of astrophysical environments from the solar corona, to planetary nebulae, to active galactic nuclei, and therefore has seen significant activity over the report period. A nearly comprehensive list of targets studied include $\mathrm{He}^{*}$ (Zhou et al. 1998), Li (Wutte et al. 1997), C (Dunseath et al. 1997; Zhang \& Sampson 1997), $C^{+}$(Smith et al. 1996), $\mathrm{O}$ (Thomas et al. 1997; Majeed \& Strickland 1998), $\mathrm{O}^{+}$(McLaughlin \& Bell 1998), $\mathrm{Ne}^{2+}$ (Ramsbottom \& Bell 1998), $\mathrm{Mg}^{5+}$ (Ramsbottom \& Bell 1997a), $\mathrm{Mg}^{7+}$ (Bhatia \& Thomas 1998), $\mathrm{Al}^{10+}$ (Stancalie et al. 1999), $\mathrm{S}^{+}$(Ramsbottom et al. 1996; Liao et al. 1997), $\mathrm{S}^{2+}$ (Tayal 1997), $\mathrm{Ar}^{2+}$ (Galavis et al. 1998), $\mathrm{Ar}^{3+}$ (Ramsbottom \& Bell 1997b), Fe (Pelan \& Berrington 1997), $\mathrm{Fe}^{3+}$ (Zhang \& Pradhan 1997), $\mathrm{Fe}^{10+}$ (Gupta \& Tayal 1999), $\mathrm{Fe}^{11+}$ (Binello et al. 1998), $\mathrm{Fe}^{12+}$ (Gupta \& Tayal 1998), Fe ${ }^{14+}$ (Bhatia et al. 1997; Griffin et al. 1998a), $\mathrm{Fe}^{15+}$ (Cornille et al. 1997), $\mathrm{Fe}^{20+}$ (Phillips et al. 1996; Zhang \& Sampson 1997), $\mathrm{Fe}^{21+}$ (Ait-Tahar et al. 1996), Fe ${ }^{23+}$ (Berrington \& Tully 1997; D'Cruz \& Sarazin 1998), $\mathrm{Co}^{+}$(Watts 1998), $\mathrm{Co}^{2+}$ (Shaw et al. 1998), $\mathrm{Ni}^{+}$(Watts et al. 1996), $\mathrm{Ni}^{2+}$ (Watts \& Burke 1998), $\mathrm{Ni}^{4+}$ (Teng et al. 1998), $\mathrm{Ni}^{1+}$ (Matthews et al. 1998), Li-like ions (Safronova et al. 1996; Burgess et al. 1998), F-like ions (Berrington et al. 1998), Na-like ions (Keenan et al. 1996; Kimura et al. 1998), and Al-like ions (Saraph \& Storey 1999). Rate coefficients for atoms and ions of $\mathrm{H}$ to $\mathrm{Ni}$ can be found in Mazzotta et al. (1998). A variety of ions 
have been studied experimentally with the merged-beamed technique at ORNL with much of the data accessible via the WWW (e.g., $\mathrm{Si}^{2+}$, Wallbank et al. 1997).

Electron-impact ionization of atoms and ions has seen significant advances in theoretical methods particularly involving studies of $\mathrm{H}$ targets. These include time-dependent lattice methods (Robicheaux et al. 1997), convergent close-coupling and R-matrix approaches (Scott et al. 1997), and time-dependent close-coupling methods (Pindzola \& Robicheaux 1996). Theoretical data on various relevant target species include $\mathrm{H}^{*}, \mathrm{Li}, \mathrm{O}^{5+}, \mathrm{Na}$, and K (Bray 1996), $\mathrm{C}^{+}$(Qian \& Pan 1998), Li-like ions (Chen et al. 1996), Na-like ions (Pindzola et al. 1998), and $\mathrm{Mg}$-like, Cu-like, and $\mathrm{Zn}$-like ions (Badnell 1999). A tabulation of analytical ionization rate coefficients for all atoms and ions of $\mathrm{H}$ to $\mathrm{Ni}$ has been compiled by Voronov (1997) and for all carbon ions by Chang \& Ordonez (1998). Majeed \& Strickland (1998) have surveyed the data for O, and Bannister (1996; see also for other experiments) has measured the ionization cross section for some Ne ions with the ORNL crossed-beam apparatus.

A multitude of data for radiative recombination (RR) and dielectronic recombination can be found on the WWW (Verner et al. 1999; Pindzola et al. 1999). Specific systems which have been studied recently include $\mathrm{Li}^{+}$(Zavodszky et al. 1998), all C ions (Nahar \& Pradhan 1997; Safronova \& Kato 1996, 1998), all N ions (Nahar \& Pradhan 1997), all $\mathrm{O}$ ions (Nahar 1999), $\mathrm{Ne}^{2+}$ (Kisielius et al. 1998), $\mathrm{Ne}^{7+}$ (Zong et al. 1998), many Fe ions (Nahar et al. 1997, 1998; Moribayashi et al. 1997; Nahar \& Bautista 1999), $\mathrm{Fe}^{21+}$ (Chen et al. 1998), $\mathrm{Fe}^{24+}$ (Gorczyca \& Badnell 1997), C-like ions (Nahar 1996), F-like and Ne-like ions (Jacquemot et al. 1998). However, in recent years three issues have arisen which may call into question the reliability of theoretical electron-ion recombination data or its use in particular environments. In the former instance it has been argued by Badnell et al. (1998) that the neglect of radiation damping effects on low-energy resonances can result in a significant overestimation of $\mathrm{RR}$ rate coefficients. On the other hand, at very low energies, experiments ( $\mathrm{Gao}$ et al. 1997) on ion storage rings have measured $\mathrm{RR}$ rate coefficients which are much larger than suggested by theory. Measurements of dielectronic recombination in well-defined electric fields find an enhancement which should be important in astrophysical environments except those with an extremely low ionization fraction (Savin et al. 1996). Some calculations in electric fields have been performed by Griffin et al. (1998b).

Elastic collisions between electrons and atoms/ions can be crucial in determining the transport properties of electrons in plasmas/gases and so we note several recent works on elastic electron scattering: He (Fursa and Bray 1997), $\mathrm{N}^{1-6+}$ (Greenwood \& Williams 1997), and O (Agrawal \& Baluja 1996). Mayol \& Salvat (1997) have given a tabulation for all neutral atoms of $\mathrm{H}$ through $\mathrm{U}$.

\subsection{Electron Impact of Molecules}

Electron collisional excitation of molecules is an important process in many plasma environments including planetary atmospheres and high-excitation nebulae. It can play a significant role in line excitation and cooling when energetic electrons are available, i.e. photo-electrons. Recent studies of rotational excitation include $\mathrm{H}_{2}$ (Danby et al. 1996), $\mathrm{HeH}^{+}$and $\mathrm{NO}^{+}$(Rabadán et al. 1998), $\mathrm{CO}$ (Randell et al. 1996), $\mathrm{O}_{2}$ (Mukherjee \& Ghosh 1996), $\mathrm{H}_{2} \mathrm{O}$ (Gianturco et al. 1998a), $\mathrm{O}_{3}$ (Gianturco et al 1998b), $\mathrm{CO}_{2}$ (Gianturco \& Stoecklin 1997), and $\mathrm{SO}_{2}$ (Gianturco et al. 1997). Vibrational excitation due to electron collisions has been investigated for $\mathrm{H}_{2}$ (Lee et al. 1996a; Kazanskii 1996; Mazevet et al. 1998), HD (Kazanskii 1996), $\mathrm{N}_{2}$ (Grimm-Bosbach et al. 1996; Sweeney \& Shyn 1997), OH (Chen \& Morgan 1997), $\mathrm{CO}$ (Gibson et al. 1996), and $\mathrm{CH}_{4}$ (Bundschu et al. 1997) while studies of electronic excitation of $\mathrm{H}_{2}$ (Celiberto et al. 1996), $\mathrm{CO}$ (Lee et al. 1996b; Zubek et al. 1997; Zetner et al. 1998), $\mathrm{CO}, \mathrm{CO}_{2}$, and $\mathrm{SO}_{2}$ (Fomunung et al. 1996), $\mathrm{N}_{2}$ (Gillan et al. 1996), NO (Mojarrabi et al. 1996), $\mathrm{O}_{3}$ (Sweeney \& Shyn 1996), $\mathrm{H}_{2} \mathrm{O}$ (Morgan 1998), $\mathrm{H}_{2} \mathrm{~S}$ (Michelin et al. 1997), and $\mathrm{CH}_{4}$ and $\mathrm{SiH}_{4}$ (Bettega et al. 1998) have been performed.

Cross sections have been measured or calculated for ionization of $\mathrm{H}_{2}, \mathrm{~N}_{2}, \mathrm{O}_{2}, \mathrm{H}_{2} \mathrm{O}$, and $\mathrm{CO}_{2}$ (Straub et al. 1996a, 1996b, 1998), $\mathrm{H}_{2}$ and $\mathrm{H}_{2} \mathrm{O}$ (McCarthy 1996); dissociation 
of $\mathrm{H}_{2} \mathrm{O}$ (Kedzierski et al. 1998; Tarnovsky et al. 1998), $\mathrm{N}_{2} \mathrm{O}$ (Furuhashi et al. 1997); and dissociation and ionization of $\mathrm{H}_{2}$ (Celiberto et al. 1997), $\mathrm{CO}^{+}$(Belic et al. 1997), $\mathrm{N}_{2}, \mathrm{O}_{2}$, $\mathrm{CO}_{2}$, and $\mathrm{CH}_{4}$ (Tian \& Vidal 1997, 1998a, 1998b, 1998c), and $\mathrm{C}_{2} \mathrm{H}_{2}$ (Zheng \& Srivastava 1996). Theoretical ionization cross sections are available for $\mathrm{H}_{2}, \mathrm{~N}_{2}, \mathrm{O}_{2}, \mathrm{CO}, \mathrm{H}_{2} \mathrm{O}$, and $\mathrm{CO}_{2}$ (Hwang et al. 1996), $\mathrm{H}_{2} \mathrm{O}$ (Liu et al. 1997), and $\mathrm{C}_{60}$ (Deutsch et al. 1996) and Majeed \& Strickland (1998) have compiled ionization data for $\mathrm{N}_{2}$ and $\mathrm{O}_{2}$. A recommended $\mathrm{H}_{2}$ dissociation cross section has been constructed by Martin et al. (1998).

The process of dissociative recombination (DR), in which an electron is captured by a molecular ion, with the resulting neutral intermediary dissociating into a number of neutral products, is an important process in many astrophysical environments. DR is an efficient mechanism for producing complex neutral molecules, but it has proven difficult to study experimentally and theoretically. However, the recent development of heavy-ion storage rings has allowed for accurate determinations of low-energy cross sections and productstate branching ratios, the latter of great importance to astrochemical studies of interstellar clouds. An improved understanding of the reaction mechanism has also allowed for accurate calculations with multichannel quantum defect and R-matrix methods. Molecular ions which have been studied during the report period include $\mathrm{H}_{2}^{+}$(van der Zande et al. 1996), $\mathrm{HeH}^{+}$(Orel \& Kulander 1996; Strömholm et al. 1996), $\mathrm{H}_{2} \mathrm{O}^{+}$and $\mathrm{H}_{3} \mathrm{O}^{+}$(Vejby-Christensen et al. 1997), $\mathrm{CH}_{2}^{+}$(Larson et al. 1998), $\mathrm{CH}_{3}^{+}$(Vejby-Christensen et al. 1997), $\mathrm{CH}_{5}^{+}$ (Semaniak et al. 1998), $\mathrm{CN}^{+}$(Le Padellec et al. 1999), $\mathrm{CO}^{+}$(Rósen et al. 1998), and $\mathrm{HCO}^{+}$(Le Padellec et al. 1997).

Recent work on elastic collisions between electrons and molecules include $\mathrm{H}_{2}$ and $\mathrm{N}_{2}$ (Isaacs \& Morrison 1996), NO (Da Paixao et al. 1996), $\mathrm{CO}_{2}$ (Gianturco \& Stoecklin 1996), $\mathrm{CO}$ (Gibson et al. 1996), $\mathrm{CO}_{2}$ (Takekawa \& Itikawa 1996), $\mathrm{O}_{2}$ (Green et al. 1997), $\mathrm{H}_{2} \mathrm{O}$ (Gianturco et al. 1998a), $\mathrm{O}_{3}$ (Sarpal et al. 1998), $\mathrm{CO}_{2}$ (Tanaka et al. 1998), $\mathrm{CO}, \mathrm{N}_{2}, \mathrm{NO}$, and $\mathrm{O}_{2}$ (Liu \& Sun 1996), and $\mathrm{CO}, \mathrm{CO}_{2}, \mathrm{CH}_{4}, \mathrm{C}_{2} \mathrm{H}_{4}$, and $\mathrm{C}_{2} \mathrm{H}_{6}$ (Maji et al. 1998).

\subsection{Ion-Atom and Atom-Atom Collisions}

Though a very large range of species involved in ion-atom and atom-atom collisions has recently been studied, of principal interest in astrophysics have been collisions involving the abundant species such as $\mathrm{H}, \mathrm{H}_{2}, \mathrm{He}, \mathrm{C}, \mathrm{N}$, and $\mathrm{O}$.

For example, chemistry in nebulae often involves the transfer of an electron between ions and atoms through low energy collisions, or strong magnetic fields can accelerate ions which precipitate into the atmospheres of planets or stream through clouds of ejecta, capturing electrons from the gas atoms. Recent works have considered charge transfer in the following collisions: $\mathrm{O}^{3+}+\mathrm{H}$ (Beijers et al. 1996), $\mathrm{H}^{+}+\mathrm{C}, \mathrm{N}, \mathrm{O}, \mathrm{Si}$ (Kimura et al. 1997), $\mathrm{C}^{+}+\mathrm{H}$ (Stancil et al. 1998a), $\mathrm{N}^{2+}+\mathrm{H}$ (Pieksma et al. 1997), $\mathrm{Si}^{4+}+\mathrm{H}$, $\mathrm{D}$ (Wu \& Havener 1997), $\mathrm{C}^{5+}+\mathrm{He}$ (Fritsch \& Lin 1996), $\mathrm{Si}^{3+}+\mathrm{He}$ (Fang \& Kwong 1997; Stancil et al. 1999), $\mathrm{O}^{+}+\mathrm{O}$ (Hickman et al. 1997), and $\mathrm{C}^{2+}+\mathrm{He}$ (McCullough et al. 1997). Kingdon \& Ferland (1996) have provided analytical fits for low-energy charge transfer between multiply-charged ions and $\mathrm{H}$ and made them available on the WWW. Cross sections have been computed for charge transfer between $\mathrm{H}$ and all $\mathrm{H}$-like ions by Harel et al. (1998) and for resonant charge transfer of neutral and singly ionized atoms from $\mathrm{H}$ to $\mathrm{Ca}$ (Copeland \& Crothers 1997).

Of particular importance to transport in $\mathrm{H} / \mathrm{H}_{2}$ plasmas, such as planetary ionospheres, the heliospheric shock interface with the ISM, comet bow shocks, etc., is the elastic scattering cross section and its related moments (e.g. momentum transfer and viscosity cross sections). Recent work has computed the elastic differential cross section at a large number of energies between 0.1 and $100 \mathrm{eV}$ and the corresponding integral elastic and transport moments for $\mathrm{H}^{+}, \mathrm{D}^{+}, \mathrm{H}, \mathrm{D}+\mathrm{H}, \mathrm{D}, \mathrm{He}$ (Krstić \& Schultz, 1999) and provided a WWW interface to the raw data. This work also cites a large part of the relevant extant literature regarding elastic collisions involving $\mathrm{H}, \mathrm{H}_{2}$, and $\mathrm{He}$. 
For thermal (e.g., 100-10,000 K) plasmas or for ions accelerated by strong fields (e.g. $10^{4}-10^{7} \mathrm{~K}$ ) excitation and ionization can also be of significant interest. Notable examples of results for excitation include proton impact excitation for Be-like (Ryan et al. 1998), B-like (Foster et al. 1997), C-like (Ryan et al. 1999), and Be-like to Cl-like ions (Copeland et al. 1997). Regarding ionization, the following works are of particular interest: $\mathrm{He}^{*}+\mathbf{H}$ (Mihajlov et al. 1996), $\mathrm{H}+\mathrm{H}$ (Krstić et al. 1996), $\mathrm{H}^{+}+\mathrm{O}$ (Thompson et al. 1997), $\mathrm{H}^{+}$, $\mathrm{He}^{2+}, \mathrm{Li}^{3+}+\mathrm{H}$ (Toshima 1997), and $\mathrm{H}^{+}+\mathrm{H}$ (Shah et al. 1998).

Ion-atom and atom-atom collisions can also create molecules through radiative association and associative attachment. Babb \& Kirby (1998) have surveyed the available literature up to 1997. More recent results include radiative association formation of $\mathrm{HeH}^{+}$ (Zygelman et al. 1998), CO, $\mathrm{CS}^{+}$, and $\mathrm{SiN}$ (Singh et al. 1999), $\mathrm{C}_{2}, \mathrm{C}_{2}^{+}, \mathrm{N}_{2}^{+}$, and $\mathrm{Si}_{2}$ (Andreazza \& Singh 1997).

Also noteworthy is the fact that an increasing number of investigations are seeking to provide information about atomic collisions involving strong external fields, and may soon provide new data needed in astrophysical modeling. Furthermore, a number of recent works have shown that the generally expected smooth decline of inelastic (e.g. excitation, ionization, non-resonant charge transfer) cross sections toward threshold, down from their peak at higher energies, might quite ubiquitously have oscillations superimposed (Schultz et al. 1997; Horvath et al. 1996; Krstić et al. 1998; DeHeer et al. 1992).

\subsection{Ion-Molecule and Atom-Molecule Collisions}

For astrophysical gas at lower temperatures and higher densities, collisions of ions and atoms with molecules become increasingly important. Examples include the precipitation of accelerated ions into a dense planetary atmosphere and dense primordial clouds cooled by radiating molecules excited through collisions.

Regarding charge transfer for ion-molecule collisions, recent works of interest include the following collisions: $\mathrm{N}^{+}+\mathrm{H}_{2} \mathrm{O}$ (Dressler et al. 1995), $\mathrm{O}^{3+}+\mathrm{H}_{2}$ (Beijers et al. 1996), $\mathrm{C}^{2-4+}+\mathrm{H}_{2}, \mathrm{CH}_{4}, \mathrm{CO}_{2}$ (Itoh et al. 1995), $\mathrm{H}^{+}, \mathrm{D}^{+}+\mathrm{H}_{2}$ (Ichihara et al. 1996), $\mathrm{He}^{2+}$, $\mathrm{Li}^{3+}, \mathrm{C}^{4+}, \mathrm{N}^{5+}+\mathrm{H}_{2}$ (Kumar \& Saha 1998), $\mathrm{H}^{+}+\mathrm{C}_{2} \mathrm{H}_{2}$ (Kimura et al. 1996), $\mathrm{C}^{2+}+\mathrm{H}_{2}$ (McCullough et al. 1997), $\mathrm{H}^{+}+\mathrm{N}_{2}, \mathrm{O}_{2}$ (Siegmann et al. 1998), and $\mathrm{O}^{+}+\mathrm{N}_{2}$ (Lindsay et al. 1998).

As described above, a recent work has extensively investigated the elastic and transport cross sections for $\mathrm{H} / \mathrm{H}_{2}$ plasmas/gases and provides on the WWW, tabulations of the differential and integral cross sections for $\mathrm{H}^{+}, \mathrm{D}^{+}, \mathrm{H}, \mathrm{D}+\mathrm{H}_{2}, \mathrm{D}_{2}, \mathrm{HD}$ (Krstić \& Schultz 1999).

Rotational and vibrational excitation of molecules is the primary mechanism for populating excited rovibrational states and for radiative cooling in low ionization environments. Rate coefficients have been computed for rovibrational excitation of $\mathrm{H}_{2}$ by $\mathrm{H}, \mathrm{He}$, and $\mathrm{H}_{2}$ impact (Le Bourlot et al. 1999; Balakrishnan et al. 1997, 1999; Forrey et al. 1997); of HD by $\mathrm{H}$ (Roueff \& Flower 1999), He (Roueff \& Zeippen 1999), and $\mathrm{H}_{2}$ impact (Flower 1999); and of $\mathrm{CO}$ by $\mathrm{H}$ impact (Green et al. 1996). Also of interest are recent works describing ionization of astrophysically important molecules: $\mathrm{He}^{*}+\mathrm{H}_{2} \mathrm{O}, \mathrm{H}_{2}, \mathrm{~N}_{2}$ by Ishida (1996), Vojtik (1996), and Ishida \& Horime 1996), respectively, $\mathrm{H}+\mathrm{N}_{2}$ (Quintana \& Pollack 1996), and $\mathrm{He}^{+}+\mathrm{H}_{2}$ (Hsu et al. 1996),

Of significant interest to circumstellar, interstellar, primordial cloud, planetary atmosphere and other environments, in which molecules can survive, is dissociation. Recent works of interest include the following: $\mathrm{H}, \mathrm{He}, \mathrm{H}_{2}+\mathrm{H}_{2}$ (Martin et al. 1998), $\mathrm{He}+\mathrm{H}_{2}$ (Sakimoto 1997), $\mathrm{He}+\mathrm{HeH}^{+}$(Coelho et al. 1996; Prior \& Brauning 1998), $\mathrm{H}^{+}, \mathrm{He}^{+}, \mathrm{O}^{6+}$ $+\mathrm{H}_{2} \mathrm{O}, \mathrm{N}_{2}$ (Werner et al. 1997), $\mathrm{He}+\mathrm{H}_{3}^{+}$(Peko et al. 1996), $\mathrm{He}+\mathrm{CO}_{2}^{+}$(Bhardwaj et al. 1998), $\mathrm{He}^{2+}+\mathrm{CO}$ (Folkerts et al. 1997), $\mathrm{H}^{+}, \mathrm{Li}^{2+}, \mathrm{C}^{3-6+}, \mathrm{F}^{4-9+}, \mathrm{Si}^{9-11,17+}+\mathrm{H}_{2}, \mathrm{CO}$, $\mathrm{CH}_{4}$ (Ben-Itzhak et al. 1997), $\mathrm{Na}^{2+}+\mathrm{H}_{2}$ (Fayeton et al. 1998), and $\mathrm{He}^{*}+\mathrm{CO}_{2}$ (Arfa et al. 1998). Of course, the formation of molecules precedes their dissociation (cf. review by Babb \& Kirby 1998 on association processes). A recent study of the formation of $\mathrm{CH}_{5}^{+}$ 
by the radiative association of $\mathrm{CH}_{3}^{+}$with $\mathrm{H}_{2}$ was given by Talbi \& Bacchus-Montabonel (1998).

\subsection{Reactive Scattering and Chemistry}

There is insufficient space to review the advances in reactive scattering. Therefore, we refer the reader to the following compilations. A database of 3864 gas-phase reactions important for interstellar and circumstellar chemistry has been compiled by Millar, Farquhar, \& Willacy (1997). The reaction rate coefficient fits are available on the WWW. Stancil, Lepp, \& Dalgarno $(1996,1998 b)$ and Abel et al. (1997) have compiled a set of gas-phase reaction rate coefficients for primordial gas $(\mathrm{H}, \mathrm{D}, \mathrm{He}$, and $\mathrm{Li})$ with the latter available on the WWW. Two important experimental studies are worth mentioning: Canosa et al. (1997) have studied reactions of $\mathrm{CH}$ with a number of complex hydrocarbons and Decker, Adams, \& Babcock (1999) have investigated $\mathrm{HS}_{2} \mathrm{H}^{+}$colliding with a variety of complex molecules.

Acknowledgments. The work of D. R. S. was supported by the U. S. Department of Energy under Contract DE-AC05-96OR22464 and that of P. C. S. by a grant from the NASA AISR Program.

\section{References}

Abel, T., et al. 1997, New Astro., 2, 181; http://zeus.ncsa.uiuc.edu: 8080/ abel/PGas

Agrawal, A. \& Baluja, K. L. 1996, Z. Phys. D, 37, 187

Ait-Tahar, S., et al. 1996, Phys.Rev.A, 54, 3984

Andreazza, C. M. \& Singh, P. D. 1997, MNRAS, 287, 287

Arfa, M. B., et al. 1998, J. Phys. B, 31, 4813

Babb, J. F. \& Kirby, K. P. 1998 in The Molecular Astrophysics of Stars and Galaxies, ed. T. W. Hartquist \& D. A. Williams (Oxford: Clarendon), 11

Badnell, N. R. 1999, http:// www-cfadc.phy .ornl.gov/data_and_codes/aurost/aurost_ioniz/home.html

Badnell, N. R., Gorczyca, T. W., \& Price, A. D. 1998, J. Phys. B, 31, L239

Balakrishnan, N., Forrey, R. C., \& Dalgarno, A. 1997, Chem. Phys. Lett., 280, 1; 1999, ApJ, 514, 520

Bannister, M. E. 1996, Phys.Rev.A, 54, 1435; http://www-cfadc.phy.ornl.gov/xbeam/xbmintro.html

Beijers, J. P. M., Hoekstra, R., \& Morgenstern, R. 1996, J. Phys. B, 29, 1397

Belic, D. S., et al. 1997, J. Phys. B, 30, 5535

Ben-Itzhak, I., et al. 1997, Phys. Scr., T73, 259

Berrington, K. A. \& Tully, J. A. 1997, A\&AS, 126, 105

Berrington, K. A., Saraph, H. E., \& Tully, J. A. 1998, A\&AS, 129, 161

Bettega, H. M. F., Ferreira, L. G., \& Lima, M. A. P. 1998, Phys.Rev.A, 57, 4987

Bhardwaj, V. R., et al. 1998, Phys.Rev.A, 58, 2834

Bhatia, A. K., Mason, H. E., \& Blancard, C. 1997, At. Data Nucl. Data Tables, 66, 83

Bhatia, A. K. \& Thomas, R. J. 1998, ApJ, 497, 483

Binello, A. M., Mason, H. E., \& Storey, P. J. 1998, A\&AS, 127, 545

Bray, I. 1996, Can. J. Phys., 74, 875

Bundschu, C. T., et al. 1997, J. Phys. B, 30, 2239

Burgess, A., Chidichimo, M. C., \& Tully, J. A. 1998, A\&AS, 131, 145

Canosa, A., Sims, I. R., Travers, D., Smith, I. W. M., \& Rowe, B. R. 1997, A\&A, 323, 644 
Celiberto, R., et al. 1996, Chem. Phys. Lett., 256, 575; 1997, Chem. Phys. Lett., 278, 154

CFADC 1999, www-cfadc.phy.ornl.gov

Chang, Y. \&

http://www-cf adc.phy . ornl.gov

Ordonez, C. A. 1998, Chem. Phys., 231, 27

Chen, C., et al. 1996, At. Data Nucl. Data Tables, 64, 301

Chen, M. H., et al. 1998, Phys.Rev.A, 58, 4539

Chen, X. \& Morgan, L. A. 1997, J. Phys. B, 30, 3709

CIAMDA 80, 1980, Computer Index to Atomic and Molecular Collision Data (Vienna: International Atomic Energy Agency); CIAMDA 87, 1987; CIAMDA 98, 1998

Coelho, L. F. S., et al. 1996, J. Phys. B, 29, 73

Copeland, F. B. M. \& Crothers, D. S. F. 1997, At. Data Nucl. Data Tables, 65, 273

Copeland, F. B. M., Reid, R. H. G., \& Keenan, F. P. 1997, At. Data Nucl. Data Tables, 67,179

Cornille, M., et al. 1997, A\&A, 320, 333

Danby, G., et al. 1996, J. Phys. B, 29, 2265

Da Paixao, F. J., Lima, M. A. P., \& McKoy, V. 1996, Phys.Rev.A, 53, 1400

D'Cruz, N. L. \& Sarazin, C. L. 1998, ApJ, 501, 414

Decker, B. K., Adams, N. G., \& Babcock, L. M. 1999, Int. J. Mass Spectro., 185, 727

DeHeer, F. J., Hoekstra, R., \& Summers, H. P. 1992, At. and Plasma-Material Interaction Data for Fusion, 3,47

Deutsch, H., et al. 1996, J. Phys. B, 29, 5175

Dressler, R. A., Arnold, S. T., \& Murad, E. 1995, J. Chem. Phys., 103, 9989

Dunseath, K. M., et al. 1997, J. Phys. B, 31, 277

Fang, Z. \& Kwong, V. H. S. 1997, ApJ, 483, 527

Fayeton, J. A., et al. 1998, Phys. Rev. A, 57, 1058

Flower, D. R. 1999, J. Phys. B, 32, 1755

Folkerts, H. O., et al. 1997, J. Phys. B, 30, 5833

Fomunung, I. W., Chen, Z., \& Mzezane, A. Z. 1996, Phys.Rev.A, 53, 806

Forrey, R., Balakrishnan, N., Dalgarno, A., \& Lepp S. 1997, ApJ, 498, 1000

Foster, V. J., Reid, R. H. G., \& Keenan, F. P. 1997, MNRAS, 288, 973

Fritsch, W. \& Lin, C. D. 1996, Phys.Rev.A, 54, 4931

Furuhashi, O., et al. 1997, J. Phys. B, 30, 3287

Fursa, D. V. \& Bray, I. 1997, J. Phys. B, 30, 757

Galavis, M. E., Mendoza, C., \& Zeippen, C. J. 1998, A\&AS, 133, 245

Gao, H., et al. 1997, J. Phys. B, 30, L499

Gianturco, F. A. \& Stoecklin, T. 1996, J. Phys. B, 29, 3933; 1997, Phys.Rev.A, 55, 1937

Gianturco, F. A., et al. 1998a, J. Chem. Phys., 108, 4002

Gianturco, F. A., Paioletti, P., \& Sanna, N. 1997, J. Phys. B, 30, 4535; 1998b, Phys.Rev.A, 58,4484

Gibson, J. C., et al. 1996, J. Phys. B, 29, 3197

Gillan, C. J., et al. 1996, J. Phys. B, 29, 1531

Gorczyca, T. W. \& Badnell, N. R. 1997, Phys.Rev.Lett, 79, 2783

Green, M. A., et al. 1997, J. Phys. B, 30, 1813

Green, S., Keller, H.-M., Schinke, R., \& Werner, H.-J. 1996, J. Chem. Phys., 105, 5416; http://www.giss.nasa.gov/data/mcrates/

Greenwood, J. B. \& Williams, I. D. 1997, Phys. Scr., T73, 108 
Griffin, D. C., Badnell, N. R., \& Pindzola, M. S. 1998a, J. Phys. B, 31, 3713

Griffin, D. C., et al. 1998b, Phys.Rev.A, 58, 4548

Grimm-Basbach, T., et al. 1996, J. Phys. B, 29, L105

Gupta, G. P. \& Tayal, S. S. 1998, ApJ, 506, 464; 1999, ApJ, 510, 1078

Harel, C., Jouin, H., \& Pons, B. 1998, At. Data Nucl. Data Tables, 68, 279

Hickman, A. P., et al. 1997, Phys.Rev.A, 56, 4633

Horvath, G., et al. 1996, Phys.Rev.A, 54, 302

Hsu, Y.-Y., Gealy, M. W., Kerby, G. W. \& Rudd, M. E. 1996, Phys. Rev. A, 53, 297

Hwang, W., Kim, Y.-K., \& Rudd, M. E. 1996, J. Chem. Phys. 104, 2956;

http://physics.nist.gov/PhysRefData/Ionization/Xsection.html

Ichihara, A., Shirai, T., \& Yokoyama K., 1996, J. Chem. Phys., 105, 1857

Isaacs, W. A. \& Morrison, M. A. 1996, Phys. Rev. A, 53, 4215; 1996, Phys.Rev.A, 54, 3697 (Erratum)

Ishida, T. 1996, J. Chem. Phys., 105, 1392

Ishida, T. \& Horime, K. 1996, J. Chem. Phys., 105, 5380

Itoh, A., et al. 1995, J. Phys. Soc. Jpn., 64, 3255

Jacquemot, S., Cornille, M., \& Nilsen, J. 1998, Phys. Scr., 58, 203

Kazanskii, A. K. 1996, Opt. Spectrosc., 80, 798

Kedzierski, W., et al. 1998, J. Phys. B, 31, 5361

Keenan, F. P., et al. 1996, Phys. Scr., 54, 163

Kimura, E., et al. 1998, A\&AS, 132, 99

Kimura, M., Gu, J.-P., Hirsch, G., \& Buenker, R. J., 1997, Phys.Rev.A, 55, 2778

Kimura, M., Li, Y., Hirsch, G., \& Buenker, R. J. 1996, Phys.Rev.A, 54, 5019

Kingdon, J. B. \& Ferland, G. J. 1996, ApJS, 106, 205; http://www-cfadc.phy .ornl.gov/astro/jk/ct.html

Kisielius, R. S., et al. 1998, A\&AS, 133, 257

Krstić, P. S., Bent, G., \& Schultz, D. R. 1996, Phys.Rev.Lett, 77, 2428

Krstić, P. S., Reinhold, C. O., \& Schultz, D. R. 1998, J. Phys. B, 31, L155

Krstić, P. S. \& Schultz, D. R. 1999, At. Plasma-Material Interaction Data for Fusion, 8, 1; http://www-cfadc.phy .ornl.gov/elastic/home.html

Kumar, A. \& Saha, B. C. 1998, J. Phys. B, 31, L937

Larson, A., et al. 1998, ApJ, 505, 459

Le Bourlot, J., Pineau des Forêts, G., \& Flower, D. R. 1999, MNRAS, 305, 802; http://massey.dur.ac.uk/drf

Lee, M.-T., et al. 1996a, J. Phys. B, 29, 2337; 1996b, J. Phys. B, 29, 4285

Le Padellec, A., Sheehan, C., Talbi, D., \& Mitchell, J. B. A. 1997, J. Phys. B, 30, 319

Le Padellec, A., et al. 1999, J. Chem. Phys., 110,890

Liao, S., et al. 1997, ApJ, 484, 979

Lindsay, B. G., et al. 1998, Phys.Rev.A, 57, 331

Liu, Y., et al. 1997, Z. Phys. D, 42, 45

Liu, Y. \& Sun, J. 1996, Phys. Lett. A, 222, 233

Majeed, T. \& Strickland, D. J. 1998, J. Phys. Chem. Ref. Data, 26, 335

Maji, S., et al. 1998, J. Phys. B, 31, 4975

Martin, P. G., Keogh, W. J., \& Mandy, M. E. 1998, ApJ, 499, 793

Matthews, A., et al. 1998, ApJ, 492, 415

Mayol, R. \& Salvat, F. 1997, At. Data Nucl. Data Tables, 65, 55

Mazevet, S., Morrison, M. A., \& Nesbet, R. K. 1998, J. Phys. B, 31, 4437 
Mazzotta, P., et al. 1998, A\&AS, 133, 403

McCarthy, I. E. 1996, Can. J. Phys., 74, 703

McCullough, R. W., et al. 1997, Phys. Scr., T73, 179

McLaughlin, B. M. \& Bell, K. L. 1998, J. Phys. B, 31, 4317

Michelin, S. E., et al. 1997, J. Phys. B, 30, 2001

Mihajlov, A. A., Dimitrijevic, M. S., \& Djuric, Z. 1996, Phys. Scr., 53, 159

Millar, T. J., Farquhar, P. R. A., \& Willacy, K., 1997, A\&AS, 121, 139; http://saturn.ma.umist.ac.uk: $8000 /{ }^{\sim} \mathrm{tjm} /$ rate/rate.html

Mojarrabi, B., et al. 1996, Phys.Rev.A, 54, 2977

Morgan, L. A. 1998, J. Phys. B, 31, 5003

Moribayashi, K. \& Sato, T. 1997, Phys. Scr., 55, 286

Mukherjee, T. \& Ghosh, A. S. 1996, J. Phys. B, 29, 2347

Nahar, S. N. 1996, ApJS, 106, 213; 1999, ApJS, 120, 131

Nahar, S. N. \& Bautista, M. A. 1999, ApJS, 120, 327

Nahar, S. N., Bautista, M. A., \& Pradhan, A. K. 1997, ApJ, 479, 497; 1998, Phys.Rev.A, 58,4593

Nahar, S. N. \& Pradhan, A. K. 1997, ApJS, 111, 339

Orel, A. E. \& Kulander, K. C. 1996, Phys.Rev.A, 54, 4992

Peko, B. L., Champion, R. L., \& Wang, Y. 1996, J. Chem. Phys., 104, 614

Pelan, J. \& Berrington, K. A. 1997, A\&AS, 122, 177

Phillips, K. J. H., et al. 1996, ApJ, 466, 549

Pieksma, M., Bannister, M. E., Wu, W., \& Havener, C. C. 1997, Phys.Rev.A, 55, 3526

Pindzola, M. S., et al. 1998, Phys. Scr., 57, 514

Pindzola, M. S., et al. 1999, http:// www-cfadc.phy.ornl.gov/data_and_codes/aurost/aurost_recomb/home.html

Pindzola, M. S. \& Robicheaux, F. 1996, Phys.Rev.A, 54, 2142

Prior, M. H. \& Brauning, H. 1998, Phys. Rev. A, 57, R5

Qian, X. Z. \& Pan, S. F. 1998, Phys. Lett. A, 239, 364

Quintana, E. J. \& Pollack, E. 1996, Phys.Rev.A, 53, 206

Rabadán, I., Sarpal, B. K., \& Tennyson, J. 1998, J. Phys. B, 31, 2077

Ramsbottom, C. A. \& Bell, K. L. 1997a, A\&AS, 126, 543; 1997b, At. Data Nucl. Data Tables, 66, 65; 1998, At. Data Nucl. Data Tables, 68, 203

Ramsbottom, C. A., Bell, K. L., \& Stafford, R. P. 1996, At. Data Nucl. Data Tables, 63, 57

Randell, J., et al. 1996, J. Phys. B, 29, 2049

Robicheaux, F., Pindzola, M. S., \& Plante, D. R. 1997, Phys.Rev.A, 55, 3573

Rosén, S., et al. 1998, Phys.Rev.A, 57, 4462

Roueff, E. \& Flower, D. R. 1999, MNRAS, 305, 353

Roueff, E. \& Zeippen, C. J. 1999, A\&A, 343, 1005

Ryan, R. S. I., et al. 1998, A\&A, 336, 393; 1999, A\&A, 345, 663

Safronova, U. I., Safronova, U. I., \& Kato, T. 1996, Phys. Scr., 54, 68

Safronova, U. I. \& Kato, T. 1996, Phys. Scr., 53, 461; 1998, J. Phys. B, 31, 2501

Sakimoto, K. 1997, J. Phys. B, 30, 3881

Saraph, H. E. \& Storey, P. J. 1999, A\&AS, 134, 369

Sarpal, B. K. et al. 1998, J. Phys. B, 31, 1333

Savin, D. W., et al. 1996, Phys.Rev.A, 53, 280

Semaniak, J., et al. 1998, ApJ, 498, 886 
Schultz, D. R., Reinhold, C. O., \& Krstić, P. S. 1997, Phys.Rev.Lett, 78, 2720

Scott, M. P., Burke, P. G., Bartschat, K., \& Bray, I. 1997, J. Phys. B, 30, L309; http://yin.ph.flinders.edu.au:8000/CCC-WWW/

Shah, M. B., et al. 1998, J. Phys. B, 31, L757

Shaw, J. A., Pindzola, M. S., Badnell, N. R., \& Griffin, D. C. 1998, Phys.Rev.A, 58, 2920 Siegmann, B., Hippler, R., \& Lutz, H. O. 1998, J. Phys. B, 31, L675

Singh, P. D., et al. 1999, MNRAS, 303, 235

Smith, S. J. et al. 1996, ApJ, 463, 808

Stancalie, V., Burke, V. M., \& Sureau, A. 1999, Phys. Scr., 59, 52

Stancil, P. C., et al. 1998a, ApJ, 502, 1006; 1999, J. Phys. B, 32, 1523

Stancil, P. C., Lepp, S., \& Dalgarno, A. 1996, ApJ, 458, 574; 1998b, ApJ, 509, 1

Straub, H. C. et al. 1996a, J. Chem. Phys., 105, 4015; 1996b, Phys.Rev.A, 54, 2146; 1998, J. Chem. Phys., 108, 109

Strömholm, C., et al. 1996, Phys.Rev.A, 54, 3086

Sweeney, C. J. \& Shyn, T. W. 1996, Phys.Rev.A, 53, 1576; 1997, Phys.Rev.A, 56, 1384

Takekawa, M. \& Itikawa, Y. 1996, J. Phys. B, 29, 4227

Talbi, D. \& Bacchus-Montabonel, M. C. 1998, Chem. Phys., 232, 267

Tanaka, H., et al. 1998, Phys.Rev.A, 57, 1798

Tarnovsky, V., Beutsch, H., \& Becker, K. H. 1998, J. Chem. Phys., 109, 932

Tayal, S. S. 1997, ApJ, 481, 550

Teng, H., Watts, M. S. T., Burke, V. M., \& P. G. Burke 1998, J. Phys. B, 31, 1355

Thomas, M. R. J., et al. 1997, J. Phys. B, 30, 4599

Thompson, W. R., et al. 1997, J. Phys. B, 30, L207

Tian, C. \& Vidal, C. R. 1997, Chem. Phys., 222, 105; 1998a, J. Chem. Phys., 108, 929; 1998b, J. Phys. B, 31, 5369; 1998c, Phys.Rev.A, 58, 3783

Toshima, N. 1997, Phys. Scr., T73, 144

van der Zande, W. J., et al. 1996, Phys.Rev.A, 54, 5010

Vejby-Christensen, L., et al. 1997, ApJ, 483, 531

Verner, D. A., et al. 1999, http://www.pa.uky . edu/ verner/rec.html

Vojtik, J. 1996, Chem. Phys., 209, 367

Voronov, G. S. 1997, At. Data Nucl. Data Tables, 65, 1; http://www.pa.uky. edu/ verner/col.html

Wallbank, B., et al. 1997, Phys.Rev.A, 56, 3714; http: //ww-cf adc.phy.ornl.gov/meibel/home.html

Watts, M. S. T. 1998, J. Phys. B, 31, 2065

Watts, M. S. T. \& Burke, V. M. 1998, J. Phys. B., 31, 145

Watts, M. S. T., et al. 1996, J. Phys. B, 29, L505

Werner, U., et al. 1997, Nucl. Instrum. Methods Phys. Res. B, 124, 298

Wu, W. \& Havener, C. C. 1997, J. Phys. B, 30, L213

Wutte, D., et al. 1997, At. Data Nucl. Data Tables, 65, 155

Zavodszky, P. A., et al. 1998, Phys.Rev.A, 58, 2001

Zetner, P. W., et al. 1998, J. Phys. B., 31, 2395

Zhang, H. L. \& Pradhan, A. K. 1997, A\&AS, 126, 373

Zhang, H. L. \& Sampson, D. H. 1997, At. Data Nucl. Data Tables, 65, 183

Zheng, S.-H. \& Srivastava, S. K. 1996, J. Phys. B, 29, 3235

Zhou, Y., et al. 1998, J. Phys. B, 31, L959 
Zong, W., et al. 1998, J. Phys. B, 31, 3729

Zubek, M., Olszewski, R., \& Wolinski, P. 1997, J. Phys. B, 30, L791

Zygelman, B., Stancil, P. C., \& Dalgarno, A. 1998, ApJ, 508, 151

\title{
4. WORKING GROUP 4: LINE BROADENING
}

\author{
PRESIDENT: C. STEHLE \\ VICE-PRESIDENT: G. PEACH
}

The field of line broadening has been very active during the last three years, as indicated by the proceedings of the 14th International Conference on Spectral Line Shapes (ICSLS), which was held in State College (Pennsylvania, USA) in 1998 (Herman 1999) and by the Supplement 5 to the Bibliography on Atomic Line Shapes and Shifts for the period April 1992 to December 1997 (Lesage \& Fuhr, 1998). This bibliography is also available at the following World-Wide Web addresses:

http://www .mesunb.obspm.fr/travaux/SRPR1F.html

http://physlab.nist.gov/PhysRefData/Linebr/html/reffrm0.html

An Atomic, Molecular \& Optical Physics Handbook was published in 1996 (Drake 1996), and it contains two chapters (19 and 57) relevant to spectral line broadening problems. The first one, written by $A$. Gallagher, is devoted to the neutral line shapes and radiation trapping. The second, by G. Peach, summarizes helpful basic theoretical expressions, commonly used in line shapes theory.

We shall restrict our report to theoretical and experimental work that may be of interest for astrophysics, with special attention to convenience and reliability.

\subsection{Stark Broadening}

In the field of Stark broadening, the recent book, "Principles of Plasma Spectroscopy", by Griem (1997), gives a helpful, updated compilation of the two older ones by the same author (Griem 1964, 1974). The first section deals with the Stark broadening of isolated lines which may be described using a collisional approach. The lines of hydrogen, hydrogenic ions and helium are discussed separately; these lines, which are sensitive to many-body effects, require specific treatments.

Isolated Lines The semi-classical formalism provides a powerful tool for the rapid calculation of line widths and shifts with a mean accuracy of $\pm 30 \%$. As a consequence, the number of transitions considered has increased rapidly. In this period for example, data for lines of C V, P IV, P V, Be III, B III, S V, Ca IX, Ca X, Si XI, Si XIII, Na X, O VII, Mg XI, Sc X, Sc XI, Ti XI, Ti XII, K VIII,K IX (Dimitrijević \& Sahal-Bréchot 1-10) Mn II, Mn III, Ga III, Ge III, Ge IV (Popović \& Dimitrijević 1998), Xe II (Popović \& Dimitrijević 1996), Ba I, Ba II(Dimitrijević \& Sahal-Bréchot 1996b), Sr I (Dimitrijevic \& Sahal-Bréchot 1997), Mg I (Dimitrijevic \& Sahal-Bréchot 1996a) and OI (Ben Nessib \& Ben Lakhdar, 1996), have been computed. Despite the large number of tabulated results, they are accessible by internet at the Centre de Données de Strasbourg:

http://cdsweb.u-strasbg.fr/Abstract.html.

The audience of these results could be greatly enlarged if the data was also presented in the form of a data base. Alternatively, the semiempirical formulas (Dimitrijević and Konjević 1980) also give rapid results, but they are somewhat less accurate.

One notes also the large number of experimental determinations of line widths and/or shifts for the transitions: NII, NIII and NIV ( $3 s-3 p$ and $3 p-3 d$, Milosavljevic and Djenize 1998), NII (463.054 nm, Djenize and Milosavljević, 1998), Ne I (3p-3s,3p-3d, Del Val et al. 1999), B III ( $2 s-2 p$, Griem et al. 1997), Na I (467-498 nm, Kettlitz and Oltmanns 
1996), Si I $(220,250,288 \mathrm{~nm}$, Srecković et al. 1998), Si II $(386,385 \mathrm{~nm}$, Wollschlager et al. 1997), C II, N II, O II, F II and Ne II $(3 s-3 p$ and $3 p-3 p$, Blagojević et al. 1999a) Xe III ( $4 f-6 d, 5 d-4 f, 5 d-6 p, 6 p-7 s, 6 s-4 f$, Romeo y Bidegain et al. 1998), O II $\left(3 s-3 p, 3 s^{\prime}-3 p^{\prime}, 3 p-3 d, 3 p-4 s\right.$, Djenize et al. 1998), Ar I (425 nm, Djurović et al. 1997), Ar II (90 spectral lines, Pellerin et al. 1997), and the study of the variation of the widths/shifts along the Be-sequence (3s-3p, Wrubel et al. 1998), the $\mathrm{Li}$ - and $\mathrm{Be}$ - sequences (C IV, N V, O VI $3 s^{2} S-3 p^{2} P$, and B II, C III, N IV, O V $3 s^{3} S-3 p^{3} P$, Blagojević et al. $1999 \mathrm{~b}$ ), the B-like sequence (N III, O IV, F V, $3 s-3 p$ and $3 p-3 d$, Blagojević et al. 1996).

Hydrogen Lines In the case of the lines of hydrogen, extensive calculations have been carried out. For example, the tabulation of the Paschen lines, using the Model Microfield Method, give both the line centres and the line wings to an accuracy better than $15 \%$ (Stehlé 1996a). Also, precise Monte Carlo calculations of the line width of the Paschen $\alpha$ line have been made by Cardenoso et al. (1997), and this method is designed for intermediate and high density plasmas. Accurate full-profile computations have been performed for the Paschen $\alpha, \beta$ and Brackett $\alpha$ lines (Motapon et al. 1997) and the Lyman $\alpha$ line (Motapon 1998), using a quantum description of the collisions with ions and electrons. In the line centre, this description is limited to low-density plasmas.

At low density, the line shapes of hydrogen have a Lorentzian shape. An analytical expression for their width is given by Stehle (1996b), together with parameters necessary for the computation of the Holtsmark intensity in the line wings.

The far wings of the hydrogen lines exhibit molecular satellite features which, in astrophysical plasmas, are attributed to the transient formation of $\mathrm{H}-\mathrm{H}$ or $\mathrm{H}-\mathrm{H}^{+}$molecules. These satellites are used to determine the gravity in DA white dwarfs. Recent progress has been made by including the variation of the radiative dipole moment during the collision for the Lyman $\beta$ line ( $\mathrm{H}-\mathrm{H}^{+}$satellites, Allard et al. 1998a) and for the Lyman $\alpha$ line $(\mathrm{H}-\mathrm{H}$, and $\mathrm{H}-\mathrm{H}^{+}$satellites, Allard et al. 1998b).

Two new theoretical research areas have been developed. The first concerns the study of the lines of hydrogen in the presence of magnetic fields (Günter and Könies 1999, Brillant et al. 1998). These developments may be useful in the future for the characterization of magnetic stars. The second is the study of the shift and asymmetry of the Balmer $\alpha, \beta$ and $\gamma$ lines; these effects are produced by short-range interactions with the plasma charges (Günter and Könies 1997).

Helium Lines The study of the intensity and shape of forbidden transitions in helium stopped in 1975, probably because of its intrinsic difficulty. The subject has recently been revisited by Beauchamp et al. (1997), for application to Helium rich (DB) White Dwarfs, using a static approximation for the interaction between helium and the plasma ions. They calculated the line shapes for the $2 p-n s, 2 s-n p$ and $2 p-n d$ transitions which are in the optical range. The Stark widths and shifts of allowed infrared helium lines (3p-7d, 3d-7f, $3 p-9 d, 3 d-12 f, 3 p-10 d)$ have also recently been studied theoretically by Terzi et al. (1998), in the semi-classical approximation, both in the impact and quasistatic limits.

Lines of H-like Ions The study of lines of hydrogenic heavy ions is only important in opacity calculations for stellar interiors, or for the evaluation of the radiative forces in stellar envelopes. This requires the description of the full line, from the centre to the line wings. One may use the recent parametrization given for the lines of $\mathrm{C}, \mathrm{N}$ and $\mathrm{O}$ by Gonzalez et al. (1998).

\subsection{Line Broadening by Foreign Gases and Molecular Line Broadening}

Introduction and Reviews During the period 1996-9, there has again been considerable activity in the field of spectral line broadening by neutral species, both theoretically and experimentally, and much of the work has been stimulated by the need to interpret observations of the atmospheres of planets and cool stars. The proceedings of the 14th International 
Conference on Spectral Line Shapes (Herman 1999) include a special section on astrophysical and atmospheric applications. Valuable databases that provide information on many molecular species for spectroscopic studies of atmospheres have been further extended, see the reviews of Wenger \& Champion (1998), Rothman et al. (1998) and Jacquinet-Husson et al. (1999). Szudy \& Baylis (1996) have reviewed Unified Franck-Condon theory and its applications to the far wings of pressure-broadened profiles, rainbow satellites and the collisional redistribution of radiation. Gamache et al. (1998) have presented a critical review of data for the pressure broadening and shift of spectral lines of ozone.

It is not the aim of this report to be exhaustive; the papers cited have been chosen on the basis of their potential astrophysical interest. The preceding reviews contain many references, and so only papers not included in them are listed below.

Broadening of Atomic Lines Results have been obtained for the broadening of far-wing profiles of lithium lines by helium (Behmenburg et al. 1996), and general tables for calculation of the broadening of atomic $p-d, d-p, d-f$, and $f-d$ transitions by neutral hydrogen are presented by Barklem \& O'Mara $(1997,1998)$ and Barklem et al. 1998). Results for the broadening of $\mathrm{Na} \mathrm{D}$ lines by $\mathrm{O}_{2}, \mathrm{~N}_{2}, \mathrm{CO}_{2}$ and $\mathrm{H}_{2} \mathrm{O}$ and $\mathrm{Mg}$ and Ca lines by $\mathrm{N}_{2}$ are given by Nefedov et al. (1999) and El Ghazaly et al. (1999).

Broadening of Molecular Lines In addition to the research described in the reviews of Wenger \& Champion (1998), Rothman et al. (1998) and Jacquinet-Husson et al. (1999), the pressure broadening and shift of various molecular bands has been investigated either experimentally or theoretically and the molecules are listed below together with their perturbing atomic or molecular species. They are: $\mathrm{H}_{2}-\mathrm{He}, \mathrm{H}_{2}$ (Michaut et al. 1998, Joubert et al. 1999), ${ }^{12} \mathrm{CH}_{3} \mathrm{D}-\mathrm{He}, \mathrm{H}_{2}, \mathrm{~N}_{2}$ (Boussin et al. 1999), $\mathrm{H}_{2} \mathrm{~S}-\mathrm{He}, \mathrm{H}_{2}, \mathrm{~N}_{2}, \mathrm{O}_{2}$ (Flatin et al. 1999, Ball et al. 1999), CO-He, $\mathrm{Ar}$ (Sinclair et al. 1998), $\mathrm{CO}_{2}-\mathrm{He}, \mathrm{Ar}, \mathrm{CO}_{2}, \mathrm{~N}_{2}$, $\mathrm{O}_{2}$ (Rodrigues et al. 1998, Vigasin 1999, Ma et al. 1999, De Rosa et al. 1999), $\mathrm{N}_{2}-\mathrm{N}_{2}$ (Buldyreva et al. 1999), $\mathrm{NH}_{3}-\mathrm{H}_{2}, \mathrm{NH}_{3}$ (Irwin et al. 1999, Birnbaum et al. 2000), $\mathrm{N}_{2} \mathrm{O}-$ $\mathrm{He}, \mathrm{N}_{2}$ (Bouanich et al. 1998), ${ }^{16} \mathrm{O}_{2}{ }^{16} \mathrm{O}_{2}$ (Schermaul \& Learner 1999), ${ }^{16} \mathrm{O}^{18} \mathrm{O}-{ }^{16} \mathrm{O}^{18} \mathrm{O}$ (Schermaul 1999) and $\mathrm{OH}-\mathrm{He}, \mathrm{H}_{2}, \mathrm{~N}_{2}, \mathrm{O}_{2}$ (Park et al. 1999).

Collision Induced Spectra Collision-induced absorption in dense atmospheres of cool stars has been reviewed by Borysow and Jørgensen (1999). Recent publications include studies of far-infrared bands of $\mathrm{H}_{2}, \mathrm{CO}_{2}, \mathrm{O}_{2}$ and liquid methane (Brodbeck et al. 1999, Gruszka \& Borysow 1999, Moreau et al. 2000, Birnbaum et al. 1999), and of the fundamental band of $\mathrm{CO}$ broadened by $\mathrm{N}_{2}$ (Luo et al. 1999).

Data Bases Currently available are the following databases:

Spherical Top data System (STDS), http://www u-bourgogne.fr/LPUB/sTDS.html, High resolution Transmission (HITRAN-96), http://www hitran .com, and Gestion et Etude des Informations Spectroscopiques Atmosphériques (GEISA-97). (http://www.ara.polytechnique.fr/alexei_ index.html).

\section{References}

Allard, N.F., Kielkopf, J., and Feautrier, N., 1998a, A\&A, 330, 782.

Allard, N.F., Drira, I., Gerbaldi, M., Kielkopf, J. and Spielfiedel, A., 1998b, A\&A, 335, 1124.

Ball, C.D., Dutta, J.M., Beaky, M.M., Goyette, T.M. and De Lucia, F.C., 1999, J. Quant. Spectrosc. Radiat. Transfer, 61, 775.

Barklem, P.S. and O'Mara, B.J., 1997, MNRAS, 290, 102.

Barklem, P.S., O'Mara, B.J. and Ross, J.E., 1998, MNRAS, 296, 1057.

Barklem, P.S. and O'Mara, B.J., 1998, MNRAS, 300, 863 
Beauchamp, A., Wesemael, F. and Bergeron, P., 1997, ApJS, 108, 579.

Behmenburg, W., Makonnen, A., Kaiser, A., Rebentrost, F., Staemmler, V., Jungen, M., Peach, G., Devdariani, A., Tserkovnyi, S., Zagrebin, A. and Czuchaj, E., 1996, J. Phys. B: At. Mol. Opt. Phys., 29, 3891.

Ben Nessib, N. and Ben Lakhdar, Z., 1996, Physica Scripta, 54, 608.

Birnbaum, G., Buechele, A., Jiang, T., Joslin, C.G. and Goldman, S., Molec. Phys., 1999, $93,573$.

Birnbaum, G., Buechele, A., Jiang, T., Orton, G.S., Hadzibabic, Z. and John, G.R., 2000, J. Quant. Spectrosc. Radiat. Transfer, 64, 47.

Blagojević, B., Popović, M.V., Konjević, N. and Dimitrijević, M.S., 1996, Phys. Rev. E, 54,743 .

Blagojević, B., Popović, M.V. and Konjević, N., 1999a, Phys. Scripta, 59, 374.

Blagojević, B., Popović, M.V. and Konjević, N. and Dimitrijević, M.S., 1999b, J. Quant. Spectrosc. Radiat. Transfer, 61, 361.

Borysow, A. and Jørgensen, U.G., in "Spectral Line Shapes", 1999, Volume 10, 14th ICSLS, AIP Conference Proceedings 467, ed. R.M. Herman, page 207.

Bouanich, J.-P., Hartmann, J.-M., Blanquet, G. and Domenech, J.L., 1998, J. Chem. Phys., 109,6684 .

Boussin, C., Lutz, B.L., Hamdouni, A. and de Bergh, C., 1999, J. Quant. Spectrosc. Radiat. Transfer, 63, 49.

Brodbeck, C., Bouanich, J.-P., Nguyen-van-Thanh, Fu, Y. and Borysow, A., 1999, J.. Chem. Phys., 110, 4750

Brillant, S., Mathys, G. and Stehlé, C., 1998, A\&A, 339, 286.

Buldyreva, J., Bonamy, J. and Robert, D., 1999, J. Quant. Spectrosc. Radiat. Transfer, 62,321 .

Cardenoso, V. and Gigosos, M.A., 1997, J. Phys. B: At. Mol. Opt. Phys, 30, 3361.

Del Val., J.A., Aparicio, J.A. and Mar, S., 1999, ApJ, 513, 535.

De Rosa, M., Corsi, C., Gabrysch, M. and D'Amato, F., 1999, J. Quant. Spectrosc. Radiat.. Transfer, 61, 97.

Dimitrijević, M.S. and Konjević, N., 1980, J. Quant. Spectrosc. Radiat. Transfer, 24,451.

Dimitrijević, M.S. and Sahal-Bréchot, S., (1) 1996, A\&AS, 115, 351, (2) 1996, A\&AS, 119, 369, (3) 1997, A\&AS, 122, 533, (4) 1998, A\&AS, 127, 543, (5) 1998, A\&AS, 128, 359 , (6) 1998, A\&AS, 129, 155, (7) 1998, A\&AS, 130, 539, (8) 1998, A\&AS, 131, 141, (9) 1998, A\&AS, 131, 143, (10) 1998, A\&AS, 133, 227.

Dimitrijević, M.S. and Sahal-Bréchot, S., 1996a, A\&AS, 117, 127.

Dimitrijević, M.S. and Sahal-Bréchot, S., 1996b, A\&AS, 119, 529.

Dimitrijević, M.S. and Sahal-Bréchot, S., 1997, A\&AS, 122, 163.

Djenize, S. and Milosavljević, V., 1998, A\&AS, 131, 355.

Djenize, S. and Milosavljević, V., Srecković, A., 1998, J. Quant. Spectrosc. Radiat. Transfer, 59,71 .

Djurović, S., Mijatović, Z., Kobilarov, R., Konjević, N., 1997, J. Quant. Spectrosc. Radiat. Transfer, 57, 695.

Drake, G.W.F. (ed.), "Atomic, Molecular \& Optical Physics Handbook", 1996, chapters 19 and 57, AIP Press, Woodbury, New York.

El Ghazaly, M.H., Abd El Baky, A.M., Mansour, A.F. and Bassyouni, A.H., 1999, J. Quant. Spectrosc. Radiat. Transfer, 61, 729.

Flatin, D.C., Goyette, T.M., Beaky, M.M., Ball, C.D. and De Lucia, F.C., 1999, J. Chem. Phys., 110, 2087.

Gamache, R.R., Arié, E., Boursier, C. and Hartmann, J.-M., 1998, Spectrochim. Acta Part A, 54,35 . 
Gonzalez, J.F., Stehlé, C., Artru, M.C. and Massacrier, G., 1998, A\&A, 330, 1120.

Griem, H.R., 1964, "Plasma Spectroscopy", McGraw-Hill, New York

Griem, H.R., 1974, "Spectral Line Broadening by Plasmas", Academic Press, New York.

Griem, H.R., 1997, "Principles of Plasma Spectroscopy", Cambridge Monographs in Plasma Physics, Cambridge University Press

Griem, H.R., Ralchenko., Y.V. and Bray, I., 1997, Phys. Rev. E, 56, 7186.

Gruszka, M. and Borysow, A., 1999, Molec. Phys., 93, 1007.

Günter, S. and Könies, A., 1997, Phys. Rev. E, 55, 907.

Günter, S. and Könies, A., 1999, J. Quant. Spectrosc. Radiat. Transfer, 62, 425.

Herman, R.M. (ed.), "Spectral Line Shapes", 1999, Volume 10, 14th ICSLS, AIP Conference Proceedings 467.

Irwin, P.G.J., Calcutt, S.B., Sihra, K., Taylor, F.W., Weir, A.L., Ballard, J., and Johnston, W.B., 1999, J. Quant. Spectrosc. Radiat. Transfer, 62, 193.

Jacquinet-Husson, N., Arié, E., Ballard, J., Barbe, A., Bjoraker, G., Bonnet, B., Brown, L.R., Camy-Peyret, C., Champion, J.P., Chédin, A., Chursin, A., Clerbaux, C., Duxbury, G., Flaud, J.-M., Flourrié, N., Fayt, A., Graner, G., Gamache, R., Goldman, A., Golovko, Vl., Guelachvili, G., Hartmann, J.-M., Hilico, J.C., Hillman, J., Lefèvre, G., Lellouch, E., Mikhailenko, S.N., Naumenko, O.V., Nemtchinov, V., Newnham, D.A., Nikitin, A., Orphal, J., Perrin, A., Reuter, D.C., Rinsland, C.P., Rosenmann, L., Rothman, L.S., Scott, N.A., Selby, J., Sinitsa, L.N., Sirota, J.M., Smith, A.M., Smith, K.M., Tyuterev, Vl.G., Tipping, R.H., Urban, S., Varanasi, P. and Weber, M., 1999, J. Quant. Spectrosc. Radiat. Transfer, 62, 205.

Joubert, P., Bonamy, J. and Robert, D., 1999, J. Quant. Spectrosc. Radiat. Transfer, 61, 19.

Kettlitz, M. and Oltmanns, P., 1996, Phys. Rev. E, 54, 6741

Lesage, A., Fuhr, J.R., "Bibliography on Atomic Line Shapes and Shifts" (April 92 to March 98), Publications de l'Observatoire de Paris, 1998.

Luo, C., Berman, R., Predoi-Cross, A., Drummond, J.R. and May, A.D., 1999, J. Mol. Spectrosc., 196, 290.

Ma, Q., Tipping, R.H., Boulet, C. and Bouanich, J.-P., 1999, Appl. Opt. 38, 599.

Michaut, X., Saint-Loup, R., Berger, H., Dubernet, M.L., Joubert, P. and Bonamy, 1998, J., J. Chem. Phys., 109, 3856.

Milosavljević, V. and Djenize, S., 1998, A\&AS, 128, 197

Milosavljević, V., Konjević, R. and Djenize, S., 1999, A\&AS, 135, 565.

Moreau, G., Boissoles, J., Boulet, C., Tipping, R.H. and Ma, Q., 2000, J. Quant. Spectrosc. Radiat. Transfer, 64, 87.

Motapon, O., Kwato Njock, M.G., Oumarou, B. and Tran Minh, N., 1997, J. Phys. B: At. Mol. Opt. Phys., 30, 3117.

Motapon, O., 1998, A\&A, 329,792.

Nefedov, A.P., Sinel'shchikov, V.A. and Usachev, A.D., 1999, J. Quant. Spectrosc. Radiat. Transfer, 61, 73.

Park, K., Zink, L.R., Chance, K.V., Evenson, K.M. and Nolt, I.G., 1999, J. Quant. Spectrosc. Radiat. Transfer, 61, 715.

Pellerin, S., Musiol, K. and Chapelle, J., 1997, J. Quant. Spectrosc. Radiat. Transfer, 57, 377.

Popović, L.C. and Dimitrijević, M.S., 1996, A\&AS, 116, 359.

Popović, L.C. and Dimitrijević, M.S., 1998, A\&AS, 128, 203.

Rodrigues, R., Boulet, C., Bonamy, L. and Hartmann, J.-M., 1998, J. Chem. Phys., 109, 3037. 
Romeo y Bidegain, M., Iriarte, D., Bertuccelli, G. and Di Rocco, H.O., 1998, Phys. Scripta, $57,495$.

Rothman, L.S., Rinsland, C.P., Goldman, A., Massie, S.T., Flaud, J.-M., Perrin, A., Dana, V., Mandin, J.-Y., Schroeder, J., McCann, A., Gamache, R.R., Wattson, R.B., Yoshino, K., Chance, K., Jucks, K., Brown, L.R. and Varanasi, P., 1998, J. Quant. Spectrosc. Radiat. Transfer, 60, 665.

Schermaul, R. and Learner, R.C.M., 1999, J. Quant. Spectrosc. Radiat. Transfer, 61, 781. Schermaul, R., 1999, J. Quant. Spectrosc. Radiat. Transfer, 62, 181.

Sinclair, P.M., Duggan, P., Berman, R., Drummond, J.R. and May, A.D., 1998, J. Mol. Spectrosc., 191, 258.

Stehlé, C., 1996a, A\&A, 395, 677.

Stehlé, C., 1996b, Physica Scripta, T65, 183.

Szudy, J. and Baylis, W.E., 1996, Physics Reports, 266, 127.

Srećković, A., Bukvić, S. and Djenize, S., 1998, Phys. Scripta, 57, 225.

Terzi, N., Sahal-Bréchot, S. and Ben Lakhdar, Z., 1998, A\&AS, 133, 229.

Vigasin, A.A., 1999, J. Quant. Spectrosc. Radiat. Transfer, 61, 743.

Wenger, C. and Champion, J.P., 1998, J. Quant. Spectrosc. Radiat. Transfer, 59, 471.

Wollschläger, F., Mitsching, J., Meiners, D., Depiesse, M., Richou, J. and Lesage, A., 1997, J. Quant. Spectrosc. Radiat. Transfer, 58, 135.

Wrubel, Th., Ahmad, I., Büscher, S., Kunze, H.J. and Glenzer, S.H., 1998, Phys. Rev. E, 57,5972 .

\title{
5. WORKING GROUP 5: MOLECULAR STRUCTURE AND TRANSITION DATA
}

\author{
PRESIDENT: E. F. VAN DISHOECK \\ VICE-PRESIDENT: J. H. BLACK
}

The following summary has been prepared by E.F. van Dishoeck and J.H. Black, with contributions sent by S. Leach, T. Oka, F. Rostas, L. Rothman, P.L. Smith and K. Yoshino in the summer of 1999. Other topics have been added through a search of the (vast) literature. Because of space limitations, a complete overview or list of references is not possible and only a few highlights limited to gas-phase molecules of actual or potential astrophysical interest are given. With the advent of electronic versions of the astrophysical and chemical physics journals, other related references can readily be found by searching on the appropriate keywords or authors.

\subsection{Fundamental Data and Databases}

The recommended values of fundamental physical constants have been officially revised by CODATA for the first time since 1986. The new 1998 recommended values are based on all data available through 1998 December 31 and will be published in detail soon (Mohr \& Taylor 2000). The new values of constants are available electronically through the US National Institute of Standards and Technology (NIST) at http://physics.nist.gov/constants. Uncertainties in several fundamental constants have been greatly reduced by means of precise atomic spectroscopic measurements. For example, an absolute measurement of the H I 1s-2s two-photon transition frequency yielded improved values of both the Rydberg constant and the hydrogen ground-state Lamb shift (Udem et al. 1997).

The WWW is rapidly growing into the primary tool to access and search molecular data bases. For example, the GEISA databank of infrared transitions of molecules of atmospheric interest, 1997 edition, is available at $\mathrm{http}: / / \mathrm{www}$.ara.polytechnique.fr/ 
alexei index . html. The HITRAN database is available through http://www .hitran . com/ and the 1996 Edition has been presented by Rothman et al. (1998). The JPL database of microwave transitions can be found through http://spec.jpl.nasa.gov, whereas the Lovas database is accessible through http://physics.nist.gov/PhysRefData/.

The UMIST data file of rate coefficients for interstellar chemical reactions can be found at http://saturn.phy. umist.ac.uk (Millar et al. 1997). Tables with recently measured neutral-neutral reactions at low temperature are given by Rowe et al. (2000). A table with 2000 reactions appropriate for the modeling of the photochemistry of planetary atmospheres is contained in Yung \& DeMore (1998).

Optical constants of solid materials of interest in astronomy are available through http: //aragorn .astro. uni-jena. de/Group/Subgroups/Labor/Labor/odata. html (Henning et al. 1999), whereas a summary of laboratory spectra of interstellar ices can be found at http://www.strw.leidenuniv.nl/ lab. Recent reviews of laboratory experiments on solid state material and PAHs compared with ISO and other space-based data are given in d'Hendecourt, Joblin \& Jones (1999) and Ehrenfreund et al. (1999).

Infrared spectral atlases of the Sun have been published (Wallace et al. 1996), which are of value for spectroscopic studies of highly excited states of some molecules.

Links to many of the electronic molecular databases can be found through the IAU Astrochemistry working group at http://www.strw.leidenuniv.nl/ iau34. The proceedings of IAU Symposium 197 on Astrochemistry include several reviews on basic molecular processes and data needs (Minh \& van Dishoeck 2000).

\subsection{Electronic Spectra}

Small molecules: The hydrogen molecule is still intensively studied. Photoionization cross sections of $\mathrm{He}$ and $\mathrm{H}_{2}$ have been computed (Yan, Sadegpour \& Dalgarno 1998). The UV emission continuum in $\mathrm{H}_{2}$ excited by electron impact has been investigated (Abgrall et al. 1997). Laser spectroscopy has been used to probe the $86-90 \mathrm{~nm}$ spectrum of $\mathrm{H}_{2}$ at high resolution (Reinhold, Hogervorst \& Ubachs 1996) and to study some of its inter-Rydberg transitions (Ubachs, Hinnen \& Reinhold 1997). The ground state of the hydrogen molecule changes character in strong magnetic fields (Kravchenko \& Liberman 1998), which might affect the spectrum of a magnetic white dwarf (see also Detmer et al. 1997, 1998).

Work has continued on the UV spectrum and oscillator strengths of $\mathrm{CO}$. New oscillator strengths have been measured for the B-X $(0,0)$ and $(1,0)$ bands (Stark et al. 1999a) and in the A-X system (Federman et al. 1997). Measurements in this system have been extended from $v^{\prime}=9-17$ (Jolly et al. 1997) to $v^{\prime}=13-21$ for $v^{\prime \prime}=0$ (Stark et al. 1998), and $v^{\prime}=11-23$ (Eidelsberg et al. 1999). There are also new $a b$ initio calculations of the A-X transition dipole moment (Spielfiedel et al. 1999), which agree well with these and other experiments. Laboratory data and improved calculations of the intersystem transition oscillator strengths have been obtained (Rostas et al. 1999), which resolve earlier discrepancies. Tunable picosecond lasers have been used to measure lifetimes in the $\mathrm{E}^{1} \Pi v=$ 0 and $v=1$ states of three isotopic varieties of CO (Cacciani et al. 1998). High-resolution spectroscopy has been performed on the $\mathrm{A}-\mathrm{X}$ system in ${ }^{12} \mathrm{C}^{18} \mathrm{O}$ (Beaty et al. 1997). The EUV spectrum of CO excited by electron impact has been studied at high resolution (Ciocca, Kanik \& Ajello 1997), as well as the A-X system (Beegle et al. 1999). The nd triplet Rydberg series of $\mathrm{CO}$ has been studied by laser-induced fluorescence; the resulting analysis led to rotational term values and an improved value of the ionization limit (Mellinger, Vidal \& Jungen 1996).

High-resolution vacuum UV spectroscopy has been performed on $\mathrm{N}_{2}$ (Roncin, Subtil \& Launay 1998) and an atlas of the spectrum has been published in the astrophysical literature (Roncin \& Launay 1998). An on-line atlas of the spectrum of $\mathrm{N}_{2}$ has been introduced at the CfA at http://cfa-www harvard .edu/amdata/ampdata/cfamols.html; this searchable database contains linelists for the region $84 \mathrm{~nm}$ to $100 \mathrm{~nm}$, a compilation of $f$-value measurements and calculations, and a list of references. 
Laboratory measurements of the UV absorption of $\mathrm{O}_{2}$ have continued. The SchumannRunge bands have been measured in absorption at $670 \mathrm{~K}$ and new spectroscopic constants have been derived for the ground state $\mathrm{X}^{3} \Sigma_{g}^{-}$(Cheung et al. 1996). A comparative highresolution study of predissociation linewidths in the Schumann-Runge bands has been carried out (Dooley et al. 1998). Oscillator strengths in the Herzberg I system (Yoshino, Huestis \& Nicholls 1998) and in the Herzberg II system (Yoshino et al. 1999) have been presented.

Absorption cross sections of $\mathrm{H}_{2} \mathrm{O}$ at 120 to $188 \mathrm{~nm}$ have been measured by Yoshino et al. $(1996,1997)$, and the product distribution after photodissociation at $130 \mathrm{~nm}$ by Zanganeh et al. (1999). Calculations have been performed by van Harrevelt \& van Hemert (1999). Nitrogen oxides have been investigated: absorption cross sections of $\mathrm{NO}_{2}$ in the visible and UV have been recorded (Yoshino, Esmond \& Parkinson 1997), the $\beta(9,0)$ band of NO has been investigated in the vacuum UV (Yoshino et al. 1998), and the $\gamma$-band system of NO has been studied (Danielak et al. 1997).

The $\mathrm{A}^{3} \Phi-\mathrm{X}^{3} \Delta$ system ( $\gamma$ bands) of TiO has been measured in the laboratory and sunspots, providing improved molecular constants, RKR potential energy curves, and FranckCondon factors (Ram et al. 1999). Several new electronic states of TiO have been identified (Barnes, Merer \& Metha 1997). Theoretical transition moments in all the low-lying singlet and triplet systems of $\mathrm{TiO}$ have been computed (Langhoff 1997). The absorption spectrum of supersonically cooled $\mathrm{CH}_{3} \mathrm{OH}$ has been observed (Sominska \& Gedanken 1996). The $\mathrm{X}^{2} \Sigma^{+}$and $\mathrm{A}^{2} \Pi$ states of $\mathrm{SiO}^{+}$have been investigated through fast-ion-beam laser spectroscopy (Rosner et al. 1998). The emission spectrum of the A-X system of $\mathrm{SiH}$ and $\mathrm{SiD}$ has been recorded (Ram, Engleman \& Bernath 1998). Although $\mathrm{He}_{2}$ has a repulsive ground electronic state, it does possess bound excited states and discrete transitions between them: Focsa, Bernath, \& Colin (1998) have obtained new spectra and carried out a global analysis of the six lowest excited states of $\mathrm{He}_{2}$.

Recent studies of photodissociation processes include $\mathrm{SiH}^{+}$(Stancil et al. 1997), $\mathrm{SiO}$ (Jolicard et al. 1997, Drira et al. 1998), $\mathrm{CO}$ (Andic et al. 1999), and $\mathrm{CH}_{2}$ (Kroes et al. 1997),

The upper state of the $141.5 \mathrm{~nm}$ transition of $\mathrm{CH}_{2}$ has been characterized through $a b$ initio calculations by Yamaguchi \& Schaefer (1997). Several bands of $\mathrm{CH}, \mathrm{CH}^{+}$and their isotopomers have been analyzed (Bembenek 1997a,b; Bembenek, Kȩpa, \& Rytel 1997, Zachwieja 1997, Kępa et al. 1996).

Mahon et al. (1997) have determined transition probabilities in the $\mathrm{A}^{1} \mathrm{II}-\mathrm{X}^{1} \Sigma^{+}$system of CS. The $\mathrm{CS}_{2}$ spectrum has been studied by Cossard-Magos et al. $(1996,1997,1998)$. New bands in the $\mathrm{A}^{1} \Pi_{u}-\mathrm{X}^{1} \Sigma_{g}^{+}$system of $\mathrm{C}_{3}$ have been observed through laser induced fluorescence (Baker et al. 1997). A $630 \mathrm{~nm}$ band system of $\mathrm{FeH}$ has been identified with the $e^{6} \Pi-c^{6} \Sigma^{+}$transition (Goodridge, Hullah \& Brown 1998) and the $532 \mathrm{~nm}$ green bands with $e^{6} \Pi-{ }^{6} \Delta$ (Goodridge et al. 1997). Laser-induced fluorescence has been measured in ${ }^{13} \mathrm{CO}_{2}^{+} \tilde{\mathrm{A}}^{2} \Pi_{u}-\tilde{\mathrm{X}}^{2} \Pi_{g}$ (Varfalvy, Lafleur \& Larzillière 1996).

Absorption by $\mathrm{SO}_{2}$ is important in the atmospheres of Io and Venus; the UV photoabsorption cross sections of $\mathrm{SO}_{2}$ at $198-220 \mathrm{~nm}$ have been recorded with a vacuum ultraviolet Fourier transform spectrometer (Stark et al. 1999b).

Large molecules, PAHs, carbon chains and fullerenes: Considerable progress has been made recently in the investigation of large molecules in the gas phase. Only a small sample of such work can be cited. An exciting development has been the possible identification of some diffuse interstellar bands (DIBs) with an electronic transition in $\mathrm{C}_{7}^{-}$based upon laboratory spectra of gas-phase carbon-chain molecules (Tulej et al. 1998, Kirkwood et al. 1998). Extensive studies of the electronic spectra of carbon-chain molecules, radicals and ions have been conducted by Maier (1997) and co-workers (e.g., Wyss, Grutter \& Maier 1999, Grutter, Wyss \& Maier 1999), using mass selected matrix spectroscopy, supersonic slit jet plasma spectroscopy, hollow cathode spectroscopy and two color photodetachment 
spectroscopy. More observational data on DIBs are needed to confirm or refute the possible assigment of $\mathrm{C}_{7}^{-}$; see, e.g., Cami et al. (1997) and McCall et al. (1999) for recent data.

A summary of the laboratory results on the photophysics of PAHs and the astrophysical implications was given by Leach (1996a). A data base of spectra of neutral and ionized PAHs has been prepared by the NASA-Ames group (e.g., Allamandola, Hudgins \& Sandford 1999, Hudgins \& Allamandola 1999). The photoionization quantum yield of PAHs is an important parameter in astrophysical modeling of their formation and destruction, and has been measured for a series of PAHs in the $5-25 \mathrm{eV}$ range by Jochims, Baumgärtel \& Leach (1996), who also established 'rules of thump' for other species. Another important parameter is the structure-dependent photostability of PAH cations, studied by Allain et al. (1996a,b), Allain \& Leach (1997) and Jochims, Baumgärtel \& Leach (1999). Work has also been carried out on the dissociative ionization of PAHs in the $8-35 \mathrm{eV}$ photon energy range (Jochims et al. 1997). Ultraviolet pumping of PAHs has been investigated (Robinson, Beegle \& Wdowiak 1997), and electronic spectra of cold gas-phase PAH cations have been recorded (Bréchignac \& Pino 1999). Theoretical modeling of the formation and photodestruction of PAHs was performed using the new laboratory data (e.g., Allain et al. 1996a,b; 1997).

The laboratory work on fullerenes concerns ground state and triplet state absorption of neutral species, partially hydrogenated fullerenes and other fullerenes derivatives as well as studies on their non-linear optical properties. The spectra in the range $200-800 \mathrm{~nm}$ by Bensasson et al. $(1997,1998 \mathrm{a}, \mathrm{b})$ and Bini et al. (1998) provided the possibility of testing whether some of the DIBs and other aspects of interstellar extinction such as the $217 \mathrm{~nm}$ peak are due to these species. In particular, the spectra of $\mathrm{C}_{60} \mathrm{H}_{18}$ and $\mathrm{C}_{60} \mathrm{H}_{36}$ do not support the suggestion that the $217 \mathrm{~nm}$ peak is due to partially hydrogenated fullerenes. New evidence for the presence of interstellar $\mathrm{C}_{60}^{+}$has been provided by Foing \& Ehrenfreund (1997). A special issue of Journal of Physics B was devoted to Fullerenes and it includes articles on the electronic spectra of these molecules (see Leach 1996b, and other articles in that volume).

\subsection{Vibrational transitions}

$\mathrm{H}_{3}^{+}$, long assumed to be the universal protonator and the initiator of interstellar chemistry, has been detected through its vibrational transitions in the molecular material toward the deeply embedded young stellar objects GL 2136 and W 33A (Geballe \& Oka 1996). Subsequently, it has been observed in several other dense clouds (McCall et al. 1999). The agreement between the observed and model column densities provides direct support of the ion-molecule reaction scheme for the formation of interstellar molecules. Subsequent observations of $\mathrm{H}_{3}^{+}$in the diffuse interstellar medium show surprisingly high abundances, however, which cannot readily be explained by existing diffuse cloud models if the commonly accepted values for the cosmic ray ionization rate and the $\mathrm{H}_{3}^{+}$dissociative recombination rate are used (McCall et al. 1998a, b; Geballe et al. 1999)

Infrared transition probabilities and the corresponding opacity of $\mathrm{SiO}$ have been calculated by Drira et al. (1997) and Aringer et al. (1997). Hot bands in the infrared spectrum of $\mathrm{H}_{2} \mathrm{O}$ have been calculated by Viti et al. (1997).

\subsection{Rotational transitions}

For nearly 20 years, the cyanopolyyne $\mathrm{HC}_{9} \mathrm{~N}$ has been the largest molecule identified in interstellar space. This has changed with the radioastronomical detection of $\mathbf{H C}_{11} \mathrm{~N}$ by Bell et al. (1997). The CfA group led by P. Thaddeus has been very productive in the last three years in finding new spectra of carbon-chain molecules both in the laboratory (e.g., McCarthy et al. 1997, 1998, 1999) and in space. New laboratory spectra include those of $\mathrm{HC}_{n}(n=7,8,9,11), \mathrm{HC}_{2 n+1} \mathrm{~N}(n=5,6,7,8)$, carbon ring chains $\mathrm{H}_{2} \mathrm{C}_{2 n+1}(n=2,3,4)$ and $\mathrm{H}_{2} \mathrm{C}_{2 n} \mathrm{~N}(n=2,3), \mathrm{SiC}_{n}(n=3,5,6,7,8)$ and many more. The species $\mathrm{H}_{2} \mathrm{C}_{5}, \mathrm{HC}_{11} \mathrm{~N}, \mathrm{HC}_{n}$ $(n=7,8)$ have been detected in TMC-1 (Langer et al. 1997, Bell et al. 1999) and $\mathrm{SiC}_{3}$ in 
IRC+10216 (Apponi et al. 1999). The discovery of $\mathrm{SiC}_{3}$ is particularly noteworthy because this is the first time that the rhombic structure, theoretically predicted to be more stable than the linear structure, is observed in isolated form.

The submillimeter spectra of so-called 'hot cores' in massive star-forming reveal the presence of complex saturated organic molecules at high abundances (e.g., Nummelin et al. 1998). A fraction of the lines are still unidentified, but are likely due to highly-excited rotational lines in the ground-and/or excited vibrational states of known molecules or their isotopes. De Lucia, Herbst and co-workers have provided new laboratory measurements of $\mathrm{HCOOCH}_{3}$ (Oesterling et al. 1999), $\mathrm{CH}_{3} \mathrm{SH}$ (Bettens et al. 1999), $\mathrm{CH}_{3} \mathrm{OCH}_{3}$ (Groner et al. 1998), $\mathrm{C}_{2} \mathrm{H}_{5} \mathrm{OH}$ (Pearson et al. 1997), and $\mathrm{c}-\mathrm{C}_{2} \mathrm{H}_{4} \mathrm{O}$ (Pan et al. 1998) to address this problem. Updated tables of $\mathrm{CH}_{3} \mathrm{OH}$ and ${ }^{13} \mathrm{CH}_{3} \mathrm{OH}$ are provided by $\mathrm{Xu} \&$ Lovas (1997).

The rotational spectra of a wide variety of molecules containing metals and/or secondrow elements have been measured in the group of L. Ziurys, and astronomical searches for several of these species have been pursued. Recent examples of laboratory data include those of $\mathrm{NaCH}$ (Xin \& Ziurys 1998), NaS (Li \& Ziurys 1997), AlNC (Robinson, Apponi \& Ziurys 1997), FeC (Allen et al. 1996), and alkaline earth hydroxide radicals (Ziurys et al. 1996).

Terahertz spectroscopy of astrophysically relevant species in preparation of the SOFIA and FIRST missions is carried out in the Cologne group of G. Winnewisser (1997). Recent measurements include $\mathrm{NH}$ (Klaus, Takano \& Winnewisser 1997), $\mathrm{NH}_{2}$ (Muller et al. 1999), PH (Klisch et al. 1998) and SH (Klisch et al. 1996). Improved determinations of the $\mathrm{CO}$ rotational transitions have been obtained for use as secondary standards near $60 \mathrm{THz}$ (Wappelhorst et al. 1997).

\section{References}

Abgrall, H., Roueff, E., Liu, X., \& Shemansky, D.E. 1997, ApJ, 481, 557

Allain, T., Leach, S., \& Sedlmayer, E. 1996a,b, A\&A, 305, 602 \& 616

Allain, T., Leach, S., \& Sedlmayer, E. 1997, A\&A, 323, 163 \& 968

Allamandola, L.J., Hudgins, D.M., \& Sandford, S.A. 1999, ApJ, 511, L115

Allen, M.D., Pesch,T.C., \& Ziurys, L.M. 1996, ApJ 472, L57

Andic, L., Grozdanov, T., McCarroll, R., Tchang-Brillet, L. 1999, J. Phys. B, in press

Apponi, A.J., McCarthy, M.C., Gottlieb, C.A., \& Thaddeus, P. 1999, ApJ, 516, L99

Aringer, B., Jorgensen, U.G., \& Langhoff, S.R. 1997, A\&A, 323, 202

Baker, J., Bramble, S.K., \& Hamilton, P.A. 1997, J.Mol.Spec., 183, 6

Barnes, M., Merer, A.J., Metha, G.F. 1997, J.Mol.Spec., 181, 180

Beaty, L.M., Braun, V.D., Huber, K.P., \& Le Floch, A.C. 1997, ApJS, 109, 269

Beegle, L.W., Ajello, J.M., James, G.K., Dziczek, D., \& Alvarez, M. 1999, A\&A, 347, 375

Bell, M.B., Feldman, P.A., Travers, M.J., McCarthy, M.C., Gottlieb, C.A., \& Thaddeus, P. 1997, ApJ, 483, L61

Bell, M.B., Feldman, P.A., Watson, J.K.G., McCarthy, M.C., Travers, M.J., Gottlieb, C.A., \& Thaddeus, P. 1999, ApJ, 518, 740

Bembenek, Z., 1997a, J.Mol. Spec., 181, 136

Bembenek, Z., 1997b, J.Mol. Spec., 182, 439

Bembenek, Z., Kępa, R., \& Rytel, M. 1997, J.Mol.Spec., 183, 1

Bensasson, R.V., Hill, T.J., Land, E.J., Leach, S., McGarvey, D.J., Truscott, T.G., Ebenhoch, J., Gerst, M., \& Richardt, C. 1997, Chem. Phys., 215, 111

Bensasson, R.V., Bienvenée, E., Fabre, C., Janot, J.-M., Land, E.J., Leach, S., Leboulaire, V., Rassat, A., Roux, S., \& Seta, P. 1998, Chemistry: A European Journal, 4, 270

Bensasson, R.V., Bienvenée, E., Janot, J.-M., Land, E.J., Leach, S., \& Seta, P. 1998, Chem. Phys. Lett., 283, 221 
Bini, R., Ebenhoch, J., Fanti, M., Fowler, P.W., Leach, S., Orlandi, G., Richardt, Ch., Sandall, J.P.B., \& Zerbetto, F. 1998, Chem. Phys., 232, 75

Bettens, F.L., Sastry, K.V.L.N., Herbst, E., Albert, S., Oesterling, L.C., \& de Lucia, F.C. 1999, ApJ, 510, 789

Bréchignac, P., \& Pino, T. 1999, A\&A, 343, L49

Cacciani, P., Ubachs, W., Hinnen, P.C., Lyngå, C., L'Huillier, A., \& Wahlström, C.-G. 1998, ApJ, 499, L223

Cami, J., Sonnentrucker, P., Ehrenfreund, P., \& Foing, B.H. 1997, A\&A, 326, 822

Cheung, A.S.-C., Yoshino, K., Esmond, J.R., \& Parkinson, W.H. 1996 J. Mol. Spec., 178, 66

Ciocca, M., Kanik, I., \& Ajello, J.M. 1997, Phys. Rev. A, 55, 3547

Cossard-Magos, C., Horani, M., Jungen, M., \& Launay, F. 1996, J. Chem. Phys., 104, 7412

Cossard-Magos, C., LeFebvre-Brion, H., Jungen, M., \& Launay, F. 1997, J. Chem. Phys., 107,1308

Cossard-Magos, C., Jungen, M., \& Launay, F. 1998, J. Chem. Phys., 109, 6666

Danielak, J., Domin, U., Kȩpa, R., Rytel, M., \& Zachwieja, M. 1997, J.Mol.Spec., 181, 394

Detmer, T., Schmelcher, P., Diakonos, F.K., \& Cederbaum, L.S. 1997, Phys.Rev. A, 56, 1825

Detmer, T., Schmelcher, P., \& Cederbaum, L.S. 1998, Phys.Rev. A, 57, 1767

d'Hendecourt, L., Joblin, C., \& Jones, A. 1999, eds., Solid Interstellar Matter: The ISO revolution (Les Houches editions)

Dooley, P.M., Lewis, B.R., Gibson, S.T., Baldwin, K.G.H., Cosby, P.C., Price, J.L., Copeland, R.A., Slanger, T.G., Thorne, A.P., Murray, J.E., \& Yoshino, K. 1998, J. Chem. Phys., 109, 3856

Drira, I., Hure, J.M., Spielfiedel, A., Feautrier, N., \& Roueff, E. 1997, A\&A, 319, 720

Drira, I., Spielfiedel, A., Edwards, S., \& Feautrier, N. 1998, J.Q.S.R.T., 60, 1

Ehrenfreund, P., Kraft, C., Kochan, H., Pirronello, V., eds., 1999, Laboratory astrophysics and space research (Dordrecht: Kluwer), 687pp

Eidelsberg, M., Jolly, A., Lemaire, J.L., Tchang-Brillet, W.-Ü., Breton, J., \& Rostas, F. 1999, A\&A, 346, 705

Federman, S.R., Menningen, K.I., Lee, W., \& Stoll, J.B. 1997, ApJ, 477, L61

Focsa, C., Bernath, P.F., \& Colin, R. 1998, J.Mol.Spec., 191, 209

Goodridge, D.M., Hullah, D.F., \& Brown, J.M. 1998, J.Chem.Phys., 108, 428

Goodridge, D.M., Carter, R.T., Brown, J.M., \& Steimle, T.C. 1997, J.Chem.Phys., 106, 4823

Groner, P., Sieghard, A., Herbst, E., \& De Lucia, F.C. 1998, ApJ, 500, 1059

Grutter, M., Wyss, M., \& Maier, J.P. 1999, J. Chem. Phys., 110, 1492

Henning, Th., Il'in, V.B., Krivova, N.A., Michel, B., \& Voshchinnikov, N.V. 1999, A\&AS, 136,405

Hudgins, D.M. \& Allamandola, L.J. 1999, ApJ, 513, L69

Jochims, H.W., Baumgärtel, H., \& Leach, S. 1996, A\&A, 314, 1003

Jochims, H.W., Röhl, E., Baumgärtel, H., Tobita, S., \& Leach, S. 1997, Int. J. Mass Spectrom. Ion Proc., 167/168, 35

Jochims, H.W., Baumgärtel, H., \& Leach, S. 1999, ApJ, 512, 500

Jolicard, G., Zucconi, J.-M., Drira, I., Spielfieldel, A., \& Feautrier, N. 1997, J.Chem.Phys., 106,10105

Jolly, A., Lemaire, J.L., Belle-Oudry, D., Edwards, S., Malmasson, D., Vient, A., \& Rostas, F. 1997, J. Phys. B., 30, 4315

Kępa, R., Para, A., Rytel, M., \& Zachwieja, M. 1996, J.Mol.Spec., 178, 189 
Kirkwood, D.A., Linnartz, H., Gutter, M., Dopfer, O., Molylewski, T., Pachkov, M., Tulej, M., Wyss, M., \& Maier, J.P. 1998, Faraday Disc. 109, 109.

Klaus, T., Takano, S., \& Winnewisser, G. 1997, A\&A, 322, L1

Klisch, E., Klaus, Th., Belov, S.P., Dolgner, A., Schieder, R., Winnewisser, G., \& Herbst, E. 1996, ApJ, 473, 1118

Klisch, E., Klein, H., Winnewisser, G., \& Herbst, E. 1998, Zeit. für Naturf., 53A, 733

Kravchenko, Yu.P., \& Liberman, M.A. 1998, Phys.Rev. A, 57, 3404

Kroes, G.J., van Hemert, M.C., Billing, G.D., \& Neuhauser, D. 1997, J. Chem. Phys., 107, 5757

Langer, W.D., Velusamy, T., Kuiper, T.B.H., Peng, R., McCarthy, M.C., Travers, M.J., Kovacs, A., Gottlieb, C.A., \& Thaddeus, P. 1997, ApJ, 480, L63

Langhoff, S.R. 1997, ApJ, 481, 1007

Leach, S. 1996a, Zeit. f. Phys. Chemie, 195, 15

Leach, S. 1996b, J. Phys. B, 29, No. 21

Li, B.-Z. \& Ziurys, L.M. 1997, ApJ, 488, L137

Mahon, C.A., Stampanoni, A., Luque, J., \& Crosley, D.R. 1997, J.Mol.Spec., 183, 18

McCall, B.J., York, D.G., \& Oka, T. 1999, ApJ, submitted

McCarthy, M.C., Travers, M.J., Kovács, A., Gottlieb, C.A., \& Thaddeus, P. 1997, ApJS, 113,105

McCarthy, M.C., Travers, M.J., Chen, W., Gottlieb, C.A., \& Thaddeus, P. 1998, ApJ, 498, L89

McCarthy, M.C., Grabow,J.-U., Travers, M.J., Chen, W., Gottlieb, C.A., \& Thaddeus, P. 1999, ApJ, 513, 305

Mellinger, A., Vidal, C.R., \& Jungen, Ch. 1996, J.Chem.Phys., 104, 8913

Millar, T.J., Farquhar, P.R.A., Willacy, K. 1997, A\&AS, 121, 139

Minh, Y.C., \& van Dishoeck, E.F. 2000, eds., Astrochemistry: from molecular clouds to planetary systems, IAU Symposium 197 (San Francisco: ASP), in press

Mohr, P.J., \& Taylor, B.N., 2000, J. Phys. Chem. Ref. Data, to be published

Muller, H.S.P., Klein, H., Belov, S.P., Winnewisser, G., Morino, I., Yamada, E.M.T., \& Saito, S. 1999, J. Mol. Spectrosc., 195, 177

Nummelin, A., Bergman, P., Hjalmarson, A., Friberg, P., Irvine, W.M., Millar, T.J., Ohishi, M., \& Saito, S. 1998, ApJS, 117, 427

Oesterling, L.C., Sieghard, A., De Lucia, F.C., Sastry, K.V.L.N., \& Herbst, E. 1999, ApJ, 521,255

Pan, J., Albert, S., Sastry, K.V.L.N., Herbst, E., \& De Lucia, F.C. 1998, ApJ, 499, 517

Pearson, J.C., Sastry, K.V.L.N., Herbst, E., \& De Lucia, F.C. 1997, ApJ, 480, 420

Ram, R.S., Bernath, P.F., Dulick, M., \& Wallace, L. 1999, ApJS, 122, 331

Ram, R.S., Engleman, R., \& Bernath, P.F. 1998, J.Mol.Spec., 190, 341

Reinhold, E., Hogervorst, W., \& Ubachs, W. 1996, J.Mol.Spec., 180, 156

Robinson, J.S., Apponi, A.J., \& Ziurys, L.M. 1997, Chem. Phys. Lett., 278, 1

Robinson, M.S., Beegle, L.W., \& Wdowiak, T.J. 1997, ApJ, 474, 474

Roncin, J.-Y., Subtil, J.-L., \& Launay, F. 1998, J.Mol.Spec., 288, 128

Roncin, J.-Y., \& Launay, F. 1998, A\&AS, 128, 361

Rosner, S.D., Cameron, R., Scholl, T.J., \& Holt, R.A. 1998, J.Mol. Spec., 189, 83

Rostas, F., Eidelsberg, M., Jolly, A., Lemaire, J.L., LeFloch, A., \& Rostas, J. 1999, J. Chem. Phys., in press

Rothman, L.S., Rinsland, C.P., Goldman, A., Massie, S.T., Edwards, D.P., Flaud, J.-M., Perrin, A., Donna, V., Mandin, J.-Y., Schroeder, J., McCann, A., Gamache, R.R., 
Wattson, R.B., Yoshino. K., Chance, K.V., Jucks, K.W., Brown, L.R., Nemtchinov, V., \& Varanasi, P. 1998, J. Quant. Spectrosc. Radiat. Transf., 60, 665

Rowe, B., et al. 2000, in Astrochemistry: from molecular clouds to planetary systems, IAU Symposium 197, eds. Y.C. Minh \& E.F. van Dishoeck (San Francisco: ASP), in press

Sominska, E., \& Gedanken, A. 1996, J.Mol.Spec., 175, 234

Spielfiedel, A., Tchang-Brillet, W.-Ü., Dayou, F., Feautrier, N. 1999, A\&A, 346, 699

Stancil, P.C., Kirby, K., Sannigrahi, A.B., Buenker, R.J., Hirsch, G., \& Gu, J.-P.1997, ApJ, 486,574

Stark, G., Lewis, B.R., Gibson, S.T., \& England, J.P. 1998, ApJ, 505, 452

Stark, G., Lewis, B.R., Gibson, S.T., \& England, J.P. 1999a, ApJ, 520, 732

Stark, G., Smith, P.L., Rufus, J., Thorne, A.P., Pickering, J.C., \& Cox, G. 1999b, J. Geophys. Res., 104 (E7), 16585

Tulej, M., Kirkwood, D.A., Pachkov, M., \& Maier, J.P. 1998, ApJ, 506, L69

Ubachs, W., Hinnen, P.C., \& Reinhold, E. 1997, ApJ, 476, L93

Udem, Th., Huber, A., Gross, B., Reichert, J., Prevedelli, M., Weitz, M., \& Hänsch, T.W. 1997, Phys. Rev. Letters, 79, 2646

van Harrevelt, R., \& van Hemert, M.C. 1999, J. Chem. Phys., in press

Varfalvy, N., Lafleur, P., \& Larzillière, M. 1996, J.Mol.Spec., 177, 1

Viti, S., Tennyson, J., Polyansky, O.L. 1997, MNRAS, 287, 79

Wallace, L., Livingston, W., Hinkle, K., \& Bernath, P. 1996, ApJS, 106, 165

Wappelhorst, M.H., Saupe, S., Meyer, B., George, T., Urban, W., \& LeFloch, A. 1997, J. Mol. Spectrosc., 181, 357

Winnewisser, G. 1997, J. Mol. Structure, 408-409, 1

Wyss, M., Grutter, M., \& Maier, J.P. 1999, Chem. Phys. Lett., 304, 35

Xin, J., \& Ziurys, L.M. 1998, ApJ, 508, L109

Yamaguchi, Y., \& Schaefer, H.F., III, 1997, J.Chem.Phys., 106, 8753

Yan, M., Sadegpour, H.R., \& Dalgarno, A. 1998, ApJ, 496, 1044

Yoshino, K., Esmond, J.R., Parkinson, W.H., Ito, K., \& Matsui, T. 1996, Chem.Phys., 211, 387

Yoshino, K., Esmond, J.R., \& Parkinson, W.H. 1997, Chem.Phys., 221, 169

Yoshino, K., Esmond, J.R., Parkinson, W.H., Ito, K., \& Matsui, T. 1997, Chem.Phys., 215, 429

Yoshino, K., Huestis, D.L., \& Nicholls, R.W. 1998, J. Quant. Spectrosc. Radiat. Trans., 60,1091

Yoshino, K., Esmond, J.R., Parkinson, W.H., Thorne, A.P., Murray, J.E., Learner, R.C.M., Cox, G., Cheung, A.S.-C., Leung, W.-S., Ito, K., Matsui, T., \& Imajo, T. 1998, J.Chem.Phys., 109, 1751

Yoshino, K., Esmond, J.R., Parkinson, W.H., Thorne, A.P., Learner, R.C.M., \& Cox, G. 1999, J.Chem. Phys., 111, 2960

Yung, Y.L., \& DeMore, W.B. 1998, Photochemistry of Planetary Atmospheres (Oxford: Oxford University Press), $480 \mathrm{pp}$.

Zachwieja, M., 1997, J.Mol. Spec., 182, 18

Zanganeh, A., Fillion, J.H., Ruiz, J., Castillejo, M., LeMaire, J.L., Shafizadeh, N., \& Rostas, F. 1999, J. Chem. Phys., submitted

Ziurys, L.M., Fletcher, D.A., Anderson, M.A., \& Barclay, W.L. 1996, ApJS, 102, 425 


\section{WORKING GROUP 6: MOLECULAR REACTIONS ON SOLID SURFACES}

\section{PRESIDENT: S. LEACH}

There has been a continuing and increasing recognition of the astrophysical importance of interstellar, interplanetary and cometary dust and their function as sources or catalysts of cosmochemical reactions. A new interesting field where gas-surface reactions may play a role is exobiology. Various types of dust particles in diverse astrophysical situations can act as mediators of reactions between erstwhile gaseous atomic and molecular species, as low temperature matrix traps for gas phase species, and as sources of atoms and molecules ejected into the surrounding medium by temperature mediated outgassing, through violent shocks or through energy impulses resulting from exothermic reactions in the solid phase. The understanding of these processes is aided by appropriate laboratory studies and simulations, and goes hand-in-hand with new observations of interstellar, interplanetary and cometary materials made possible by recent new satellite and ground-based telescope devices. In particular, the Infrared Space Observatory (ISO) has provided much new observational evidence of the role of gas-surface interactions in astrophysical media. The interest of surface science scientists has been aroused in these astrophysical problems and some effort has been put into providing them, via review articles, workshops and meetings, with the basic information as to the nature of the observations and problems concerning astrophysical gas-surface interactions. There are now quite a few laboratory studies directed towards the chemical aspects of those molecular reactions on solid surfaces relevant to astrophysical problems and observations, in particular the formation of $\mathrm{H}_{2}$ by reaction of hydrogen atoms on interstellar grains. The present report is non-exhaustive; the division into sections may appear somewhat arbitrary but it represents a coarse-grained sorting of the information. Basic references to surface science studies and techniques were given in earlier Reports. Since the last Report there have been much development and use of scanning probe microscopies such as scanning tunneling microscopy and atomic force microscopy for the elucidation of surface structures both in clean environments and in gaseous and liquid environments (Binnig et al., 1982; Suto et al., 1996; Hamers et al., 1997; Cyr et al., 1996). One application area that is bound to have repercussions in astrophysical research on gas-surface interactions concerns chemical catalysis on a nanometer scale. An example is a study of the reaction of $\mathrm{H}_{2}$ on carbonaceous material (McIntyre et al., 1994).

\subsection{Reviews and Meetings}

(i) The role of dust in the formation of stars. Proc. ESO Workshop, Garching, 11-14 Sept. 1995. Eds. H.U. Käuf, R. Siebenmorgen, ESO Astrophys. Symp., Springer, Berlin (1996). (ii) Physics, chemistry, and dynamics of interplanetary dust. Proc. 150th Colloq. I.A.U., Gainsville, Florida, 14-18 August 1995. Eds. B.A.S. Gustafson, M.S. Hanner. Astron. Soc. Pac. Conf. Ser., 104 (1996).

(iii)Life Sciences: complex organics in space. Proc. F3.2 Symp.COSPAR Commission F, COSPAR meeting at Birmingham, UK, 14-21 July 1996. Eds. F. Raulin, J.M. Greenberg, Adv. Space Res. 19, N 7 (1997).

(iv) From stardust to planetesimals. Main lectures, Astron. Soc. Pac. Conf. Ser. 122 (1997). Contributed papers. Conference Santa Clara 24-26 June, 1996, Eds. M.E. Kress, A. G. G. M. Tielens, Y.J. Pendleton, NASA-CP-3343 (1996).

(v) Volatiles in the Earth and solar system Proc. Conf., Pasadena, September 1994. Ed. K.A.Farley, AIP Conf. Proc. 341 (1995).

(vi) Astrophysical implications of the laboratory study of presolar materials. Proc. Conf. St.Louis, 31 October-2 November 1996. AIP Conf.Proc. 402 (1997).

(vii) Molecules in astrophysics: probes and processes. Proc. 178th Symp. IAU, Leiden, 1-5 July 1996. Ed. E.F. van Dishoek, IAU Symp. 178 (1997). 
(viii) Astronomcal and biochemical origins and the search for life in the universe. Proc. 5th Int. Conf. Bioastronomy, Capri 1-5 July 1996, Eds. C.B. Cosmovici, S. Bowyer, D. Wertheimer, IAU Colloq. 161, Editrici Compositori, Bologna (1997).

(ix) Dust and molecules in evolved stars. Proc. Internat. Workshop, Manchester, 24-27 March, 1997. Eds. I. Cherchneff, T.J. Millar, Astrophys. Space Sci. 251 (1997).

(x) Chemistry and physics of molecules and grains in space. Faraday Disc., 109 (1998).

\subsection{Studies of Dust grain properties and models}

Observational constraints on dust models (Mathis et al., 1996 a,b); optical and magnetic properties of dust grains (Draine, 1996); composition of interstellar grains and ices (Sandford, 1996); chemical role of cosmic dust (Williams et al., 1996); nature of silicate core of grains (Greenberg et al., 1996); formation of $\mathrm{H}_{2}$ by $\mathrm{H}$-atom reaction with grain surfaces (Duley, 1996a; Biham et al., 1998); deuterium fractionation on grain surfaces (Rodgers et al., 1996; Tielens, 1997); formation of oxygen and nitrogen hydrides on grains (Wagenblast et al., 1996); gas-grain interactions in protostellar infall (Rawlings, 1996); sputtering of atmospheric gases by cosmic dust (Pavlov, et al., 1996); dust halo of Io (Ip, 1996); alignment of grains through interaction with gases (Lazarian, et al., 1996); catalytic models of $\mathrm{H}_{2} \mathrm{~S}$ on grains (Turner, 1996); $\mathrm{CO}_{2}$ in icy grain mantles (Grtler et al., 1996; Graauw et al., 1996; Whittet et al., 1998); grain shattering in shocks (Jones et al., 1996); generation and recombination of free radicals in dust grains (Goldanskii et al., 1996); solid-state IR features as indicators of interstellar gas-grain interactions (d'Hendecourt et al., 1996a); gas-grain chemistry implications of ISO observations (van Dishoek, 1998); grain-surface recombination of $\mathrm{HCO}+$ (Aikawa et al., 1998); inorganic dust formation in astrophysical environments (Gail et al., 1998); catalysis by dust grains in the solar nebula (Kress et al., 1997); role of grains in formation of complex molecules in interstellar molecular clouds (Tielens et al., 1997); detection of organic matter in interstellar grains (Pendleton, 1997); grain-grain collisions (Caselli et al., 1997); dust grain size distributions (O'Donnell et al., 1997); cometary gas-dust atmospheres (Kolesnichenko et al., 1997); propagation and survival of interstellar grains (Jones et al., 1997); possible role of interstellar grains in formation of aminoacids (Sorrell, 1997); rate equations for gas-grain reactions (Caselli et al., 1998); depletion test of dust grain models (Sofia, 1997); lifecycle of interstellar dust (Jones, 1997).

\subsection{Astrophysical observations}

Comparisons of organic materials in interstellar dust and the Murchison meteorite, (Pendleton, 1995); Dust in the diffuse ISM (Bernard et al., 1996); composition and state of icy surfaces in the outer solar system (Brown et al., 1997); nitrogen in ices (Whittet et al., 1996); IR spectrum of Galactic center and the composition of interstellar dust (Tielens et al., 1996); formation of methane on grains (Boogert et al., 1996); possible formation of HNCO and other molecules via surface reactions in Sgr B2 envelope and in star-forming complexes (Kuan et al., 1996; Mehrger et al., 1996); $\mathrm{H}_{2}$ observations in the LMC and relation to formation on grains (Gunderson et al., 1998); overview of interstellar dust grains (Henning, 1997).

\subsection{Laboratory studies and astrophysical modelling of carbonaceous materials}

UV spectroscopy of matrix-isolated amorphous carbon particles (Schnaiter et al., 1996); simulation of UV processing of HAC grains (Mennella et al., 1996); laboratory studies of PAHs, fullerenes and linear carbon chains in an astrophysical context (Leach, 1995); plasma processing of PAHs (Wdowiak, et al., 1995); laboratory experiments on small carbon grain analogues of cosmic dust (Mennella et al., 1995); theory of molecule - solid transition in astrophysical dust formation (Patzer et al., 1995); laboratory production of carbon grains, including those containing $\mathrm{C}_{60}$, in an arc discharge in the presence of oxygen (Saito et al., 1995); comparison of solid-state carbonaceous models of cosmic dust (Papoular et al., 1996); 
thermal effects in carbonaceous dust, (Duley, 1996); carbon grains produced in partially hydrogenated atmospheres (Blanco et al., 1996); interaction of $\mathrm{H}$ atoms with carbon surfaces as energy source for excitation of the UIR bands (Guillois et al., 1998); formation of carbon particles in cosmic environments (Frenklach et al., 1997).

\subsection{Astrophysical ices: laboratory studies and astrophysical observations}

Ion irradiation of astrophysical ices (Strazzulla et al., 1995; Strazzulla et al., 1997); UV photolysis of solid methanol (Schutte et al., 1995); UV photodesorption from water ice (Westley et al., 1995); Surface features on interstellar ice (McCoustra et al., 1996); condensation dynamics of cometary ice analogs (Patnaik et al., 1996); infrared spectroscopic properties of isolated water ice and its possible detection on grains (Ehrenfreund et al., 1996a); UV processing of interstellar ice analogs (Gerakines et al., 1996); production of cometary ice tholins (McDonald et al., 1996); enrichment of $\mathrm{CO} / \mathrm{N}_{2}$ by trapping in amorphous ice, and implications concerning comet P/Halley (Notesco et al., 1996); light flash and ionization from hypervelocity impacts on ice (Burchell et al., 1996); thermal properties of cometary ices and sublimation residua including organics (Kmle et al., 1996); laboratory database of solid $\mathrm{CO}$ and $\mathrm{CO}_{2}$ (Ehrenfreund et al., 1996b); sputtering of ices in the outer solar system (Johnson, 1996); molecular cloud sources with $\mathrm{H}_{2} \mathrm{O}$ ice bands (Brooke et al., 1996); spectropolarimetry of ice features (Hough et al., 1996); observation of solid formaldehyde (Schutte et al., 1996); observation of ozone trapped in surface ice of Ganymede (Noll et al., 1996); $\mathrm{CH}_{4}$ and its ices in Pluto and Triton (Stansberry et al., 1996); interstellar ices in comet Hyakutake (Irvine et al., 1996); water ice around protostar AFGI 2136 IRS 1 (Kastner et al., 1996); ISO view of interstellar ices, including implications of gas-grain chemistry, and related laboratory studies (Whittet et al., 1996; d'Hendecourt et al., 1996b; Boogert et al., 1997; Whittet et al., 1997; Dartois et al., 1998; Jourdain de Muizon et al., 1998; Ehrenfreund et al., 1998a), processing of methanol-rich ices (Chiar et al., 1996); apolar ices (Elsila et al., 1997; Ehrenfreund et al., 1998b); development of icy planetesimals (Stepinski et al., 1997); nature and evolution of interstellar ices (Chiar, 1997); heterogeneous reactions on inorganic oxide and water ice surfaces (Choi et al., 1997); IR ice band absorption in YSOs (Graham, 1998); ices in molecular cloud cores (Teixeira et al., 1998).

\subsection{Interplanetary dust particles, micrometeorites and meteorites}

Carbonates in Martian meteorite ALH84001 (Hutchins et al., 1997); dust particles in atmospheres of terrestrial planets and their role in prebiotic chemistry (Basiuk et al., 1996); particles in Jupiter's atmosphere from impacts of comet P/Shoemaker-Levy 9 (West, 1996); origin of presolar diamonds in meteoritic grains (Verchovsky et al., 1998); mineralogical changes in IDPs resulting from atmospheric entry heating (Keller et al., 1996).

\subsection{Other relevant topics}

Laboratory studies concerning oxygen in ice on Ganymede (Vidal et al., 1997); HCN polymers from impact of comet P/Shoemaker-Levy 9 on Jupiter (Matthews, 1997); role of comets, meteorites and planetesimals in formation of inner planet atmospheres (Owen et al., 1996; McKay et al., 1996); state of SO2 on surface of Io (Becker et al., 1997); ejection of SO2 from Io (Bishop et al., 1997); surface composition of Charon (Wright et al., 1997); transport of volatile molecules through cometary nuclei (Clemett et al., 1998); processing of cometary grains at nucleus surface (Guez et al., 1997); CO outgassing from comet HaleBopp (Lunine, 1997); solid-state greenhouse effect on icy Galilean satellites (Vidal et al., 1997); models of comet nuclei (Klinger et al., 1996; Benkhoffet al., 1996); possible relic biogenic activity in martian meteorite ALH84001 and some related issues (McKay et al., 1996; Becker et al., 1997; Bishop et al., 1997; Wright et al., 1997; Clemett et al., 1998); nucleation in Titan's lower atmosphere (Guez et al., 1997); physics and chemistry of the solar nebula (Lunine, 1997); organic degradation under simulated Martian conditions (Stoker et al., 1997). 


\section{References}

Abgrall, H., Roueff, E., Liu, X., \& Shemansky, D.E. 1997, ApJ, 481, 557

Aikawa Y., T. Umebayashi, T. Nakano, S. Miyama, 1998, Faraday Discuss., 109, 281

V.A. Basiuk, R. Navarro-Gonzlez, 1996, Astrophys. Space Sci., 236, 61

L. Becker, D.P. Glavin, J.L. Bada, 1996, Geochim. Cosmochim. Acta, 61, 475

J. Benkhoff, D.C. Boice, 1996, Planet.Space Sci., 44, 665

J.F. Bernard, F. Boulanger, F.X. Dèsert, J.- L. Puget, 1996, AIP Conf.Proc., 348, 105

O. Biham, I. Furham, N. Katz, V. Pirronello, G. Vidali, 1998, MNRAS., 296, 869

G. Binnig, H. Rohrer, C. Gerber, E. Weibel, 1982, Phys. Rev. Lett., 49, 57

J.L. Bishop, C.M. Pieters, T. Hiroi, 1997, Lunar Planet. Sci., XXVIII, 117

A. Blanco, S. Fonti, A.M. Muci, V. Orofino, 1996, ApJ., 472, 419

A.C.A. Boogert, W.A. Schutte, A.G.G.M. Tielens, D.C.B. Whittet, F.P. Helmich, P. Ehrenfreund, P.R. Wesselius, T. Graauw, T. Prusti, 1996, Astron. Astrophys., 315, L377

A.C.A. Boogert, W.A. Schutte, F.P. Helmich, A.G.G.M. Teilens, DH. Wooden, 1997, Astron. Astrophys., 317, 929

T.Y. Brooke, K. Sellgren, R.G. Smith, 1996, ApJ., 459, 209

R.H. Brown, D.P. Cruikshank, 1997, Annu. Rev. Earth Planet. Sci., 25, 243

J.R. Brucato, M.E. Palumbo, M.A. Satorre, 1997, Astron. Astrophys., 321, 618

M.J. Burchell, M.J. Cole, P.R. Ratcliff, 1996, Icarus, 122, 359

P. Caselli, T.W. Hartquist, O. Havnes, 1997, Astron. Astrophys., 322, 296

P. Caselli, T.I. Hasegawa, E. Herbst, 1998, ApJ., 495, 309

J.E. Chiar, A.J. Adamson, D.C.B. Whittet, 1996, ApJ., 472, 665

J.E. Chiar, 1997, Origins Life Evol. Biosphere, 27, 79

W. Choi, M.-T. Leu, 1997, Geophys. Res. Lett., 24, 2957

S.J. Clemett, M.T. Dulay, J.S. Gillette, X.D.F. Chillier, T.B. Mahajan, R.N. Zare, 1998, Faraday Discuss., 109, 417

D.M. Cyr, B. Venkataraman, G.W. Flynn, 1996, Chem. Mater., 8, 1600

E. Dartois, L. d'Hendecourt, F. Boulanger, M. Jourdain de Muizon, M. Breitfellner, J.-L. Puget, H.J. Habing, 1998, Astron. Astrophys., 331, 651

J.E. O'Donnell, J.S. Mathis, 1997, ApJ., 479, 806

B.T. Draine, 1996, Astron. Soc. Pac. Conf., 97, 16

W.W. Duley, 1996a, MNRAS., 279, 591

W.W. Duley, 1996b, MNRAS., 283, 343

P. Ehrenfreund, P.A. Gerakines, W.A. Schutte, M.C. van Hemert, E.F. van Dishoek, 1996a, Astron. Astrophys., 312, 263

P. Ehrenfreund, A. C. A. Boogert, P.A. Gerakines, D.J. Jansen, W.A. Schutte, A. G. G. M. Tielens, E.F. van Dishoek, 1996b, Astron. Astrophys., 315, L341

P. Ehrenfreund, E.F. van Dishoek, 1998a, Adv. Space Res., 21, 15

P. Ehrenfreund, A. Boogert. P. Gerakines, A. Tielens, 1998b, Disc. Faraday Discuss., 109, 463

J. Elsila, L.J. Allamandola, S.A. Sandford, 1997, ApJ., 479, 818

M. Frenklach, E. Feigelson, 1997, Astron. Soc. Pacific Conf. Ser., 122, 107

H.-P. Gail, E. Sedelmayer, 1998, Faraday Discuss., 109, 303

P.A. Gerakines, W.A. Schutte, P. Ehrenfreund, 1996, Astron. Astrophys., 312, 289

V.I. Goldanskii, A.G. Merzhanov, E.N. Rumanov, 1996, ApJ., 472, 656

T. de Graauw, D.C.B. Whittet, P.A. Gerakines, O.H. Bauer, D.A. Beintema, A.C.A. Boogert, D.R. Boxhoorn, J.E. Chiar, P. Ehrenfreund, H. Feuchtgruber, F.P. Helmich, 
A.M. Heras, R. Huygen, D.J.M. Kester, D. Kunze, F. Lahuis, K.J. Leech, D. Lutz, P.W. Morris, T. Prusti, P.R. Roelfsema, A. Salam, S.G. Schaeidt, W.A. Schutte, H.W. Spoon, A.G.G.M. Tielens, A. Valentijn, B. Vandenbussche, E.F. van Dishoek, P.R. Wesselius, E. Wieprecht, C.M. Wright, 1996, Astron. Astrophys., 315, L345

J.A. Graham, 1998, ApJ., 492, 213

J.M. Greenberg, L. Aigren, 1996, Astron. Astrophys., 309, 258

L. Guez, P. Bruston, F. Raulin, C. R/'egnaut, 1997, Planet. Space, Sci., 45, 611

O. Guillois, G. Ledoux, I. Nenner, R. Papoular, C. Reynaud, 1998, Faraday Discuss., 109, 335

J. Gürtler, T. Henning, C. Kömpe, W. Pfau, W. Krätschmer, D. Lemke, 1996, Astron. Astrophys., 315, L189

K.S. Gunderson, G.C. Clayton, J.C. Green, 1998, Publ. Astron. Soc. Pacific, 110, 60

R. Hamers, J.S. Hovis, S. Lee, H. Liu, J. Shan, 1997, J. Phys. Chem.B, 101, 1489

L. d'Hendecourt, P. Ehrenfreund, 1996a, Proc. ESO Workshop: The role of dust in the formation of stars, p.301

L. d'Hendecourt, M. Jourdain de Muizon, E. Dartois, M. Breitfellner, P. Ehrenfreund, J. Benit, F. Boulanger, J.L. Puget, H.J. Habing, 1996b, Astron. Astrophys., 315, L365

T. Henning, 1997, IAU Symp., 178, 343

J.H. Hough, A. Chrysostomou, D.W. Messinger, D.C.B. Whittet, D.K. Aitken, P.F. Roche, 1996, ApJ., 461, 902

K.S. Hutchins, B.M. Jakosky, 1997, Geophys. Res. Lett., 24, 819

J.I. Lunine, 1997, Origins Life Evol. Biosphere 27, 205

W.H. Ip, 1996, Geophys. Res. Lett., 23, 3671

W.M. Irvine, D. Bockele-Morvan, D.C. Lis, H.E. Matthews, N. Biver, J. Crovisier, J.K. Davies, W.R.F. Dent, D. Gautier, P.D. Godfrey, J. Keene, A.J. Lovell, T.C. Owen, T.G. Phillips, H. Rauer, P.F. Schloerb, M. Senay, K. Young, Nature, 383, 418

R.E. Johnson, 1996, Rev. Mod. Phys., 68, 305

A.P. Jones, A.G.G.M. Tielens, D.J. Hollenbach, 1996, ApJ., 469, 740

A.P. Jones, A.G.G.M. Tielens, D.J. Hollenbach, C.F. McKee, 1997, AIP Conf. Proc., 402, 595

A.P. Jones, 1997, Astron. Soc.Pacific Conf. Ser., 122, 97

M. Jourdain de Muizon, L. d'Hendecourt, P. Ehrenfreund, E. Dartois, J.J. Habing, J.-L. Puget, M. Breitfellner, 1998, Adv. Space Res., 21, 11

J.H. Kastner, D.A. Weintraub, 1996, Ap. J. Lett., 466, L103

L.P. Keller, K.L. Thomas, D.S. McKay, 1996, Astron. Soc. Pacific Conf. Ser., 104, 295

J. Klinger, A.-C. Levasseur-Regourd, N. Bouzani, A. Enzian, 1996, Planet.Space Sci., 44, 637

A.V. Kolesnichenko, M.Ya. Marov, 1997, Sol. Syst. Res., 31, 289

N.I. Kmle, G. Kargl, K. Thiel, K. Seiferlin, 1996, Planet. Space Sci., 44, 675

M.E. Kress, A.G.G.M. Tielens, 1997, Astron. Soc. Pac. Conf. Ser., 122, 149

Y.-J. Kuan, L.E. Snyder, 1996, ApJ., 470, 981

A. Lazarian, M. Efroimsky, 1996, ApJ., 466, 274

S. Leach, 1995, Planet. Space Sci., 43, 1153

J.I. Lunine, 1997, Origins Life Evol.Biosphere 27, 205

M. McCoustra, D.A. Williams, 1996, M.N.R.A.S., 279, L53

G.D. McDonald, L.J. Whited, C.DeRuiter, B.N. Khare, A. Patnaik,C. Sagan, 1996, Icarus, 122,107

D.S. McKay, E.K. Gibson Jr., K.L. Thomas-Keprta, H. Vali, C.S. Romanek, S.J. Clemett, X.D.F. Chillier, C.R. Maechlng, R.N. Zare, 1996, Science, 273, 924 
B.J. McIntyre, M. Salmeron, G.A. Somorjai, 1994, Science, 265, 1415

C.N. Matthews, 1997, Adv. Space. Res., 19, 1087

J.S. Mathis, 1996a, Astron. Soc. Pac. Conf., 97, 3

J.S. Mathis, 1996b, ApJ., 472, 643

D.M. Mehrger, L.E. Snyder, 1996, ApJ., 471, 897

V. Mennella, L. Colangeli, E. Bussoletti, P. Merluzzi, G. Monaco, P. Palumbo, A. Rotundi, 1995, Planet. Space Sci., 43, 1217

V. Mennella, L. Colangeli, P. Palumbo, A. Rotundi, W. Schutte, E. Bussoletti, 1996, ApJ. Lett., 464, L191

K.S. Noll, R.E. Johnson, A.L. Lane, D.L. Domingue, H.A.Weaver, 1996, Science, 273, 341

G. Notesco, A. Bar-Nun, 1996, Icarus, 122, 118

T. Owen, A. Bar-Nun, 1996, Earth, Moon, Planets, 72, 425

R. Papoular, J. Conard, O. Guillois, I. Nenner, C. Reynaud, J.-N. Rouzaud, 1996, Astron. Astrophys., 315, 222

A. Patnaik, K. Roessler, 1996, Spectrochim. Acta, 52A, 1085

A.B.C. Patzer, T.M. Köhler, E. Sedlmayr, 1995, Planet. Space Sci., 43, 1233

A.K. Pavlov, A.A. Pavlov, 1996, Sol. Syst. Res., 30, 289

Y.J. Pendleton, 1995 Planet. Space Sci., 43, 1359

Y.J. Pendleton, 1997, Origins Life Evol. Biosphere, 27, 53

S.D. Rodgers, T.J. Millar, 1996, MNRAS., 280, 1046

J.M.C. Rawlings, 1996, Astrophys. Space Sci., 237, 299

Y. Saito, C. Kaito, T. Sakamoto, S. Kimura, Y. Nakayama, C. Koike, 1995, Planet. Space Sci., 43, 1303

S.A. Sandford, 1996, Astron. Soc. Pac. Conf., 97, 29

M. Schnaiter, H. Mutschke, T. Henning, D. Lindakers, M. Strecker, P. Roth, 1996, Ap.J. Lett., 464, L187

W.A. Schutte, P.A. Gerakines, T.R. Geballe, E.F. van Dishoek, J.M. Greenberg, 1996, Astron. Astrophys., 309, 633

W.H. Sorrell, 1997, Astrophys. Space Sci., 253, 27

U.J. Sofia, 1997, Astron. Soc.Pacific Conf. Ser., 122, 77

J.A. Stansberry, J.R. Spencer, B. Schmitt, A.-I. Benchkoura, R.V. Yelle, J.I. Lunine, 1996, Planet. Space Sci., 44, 1051

T.F. Stepinski, P. Valageas, 1997, Astron. Astrophys., 319, 1007

C.R. Stoker, M.A. Bullock, 1997, J. Geophys. Res. 102, 10881

G. Strazzulla, A.C. Castorina, M.E. Palumbo, 1995, Planet. Space Sci., 43, 1247 G. Strazzulla, W.A. Schutte, P.A. Gerakines, 1995, Planet. Space Sci., 43, 1253

S. Suto, A. Kasuya, C.W. Hu, A. Wawr, K. Sakamoto, et al., 1996, Mater. Sci. Eng., A217, 34

T.C. Teixeira, J.P. Emerson, M.E. Palumbo, 1998, Astron. Astrophys., 330, 711

A.G.G.M. Tielens, D.H. Wooden, L.J. Allamandola, J. Bregman, F.C. Witteborn, 1996, ApJ., 461, 210

A.G.G.M. Tielens, 1997, AIP Conf. Proc., 402, 523

A.G.G.M. Tielens, S.B.Charnley, 1997, Origins Life Evol. Biosphere, 27, 23

B.E. Turner, 1996, ApJ., 468, 694

E.F. van Dishoek, 1998, Faraday Discuss., 109, 31

A.B. Verchovsky, A.V. Fisenko, L.F. Semjonova, L.P. Wright, C.T. Pillinger, 1998, Faraday Discuss., 109, 403

R.A. Vidal, D. Bahr, R.A. Bargiola, M. Peters, 1997, Science, 276, 1839 
R. Wagenblast, D.A. Williams, 1996, Astrophys. Space Sci., 236, 257

T.J. Wdowiak, W. Lee, J. Cronin, L.W. Beegle, 1995, Planet. Space Sci., 43, 1175

M.S. Westley, R.A. Baragiola, R.E. Johnson, G.A. Baratta, 1995, Planet. Space Sci., 43, 1311

D.C.B. Whittet, R.G. Smith, A.J. Adamson, D.K. Aitken, J.E. Chiar, T.H. Kerr, P.F. Roche, C.H. Smith, C.M. Wright, 1996, ApJ., 458, 363

R.A. West, 1996, IAU Colloq., 156, 269

D.C.B. Whittet, W.A. Schutte, A.G.G.M. Tielens, A.C.A. Boogert, T. Graauw, P. Ehrenfreund, P.A. Gerakines, F.P. Helmich, T.Prusti, E.F. van Dishoek, 1996, Astron. Astrophys., 315, L357

D.C.B. Whittet, 1997, Origins Life Evol. Biosphere, 27, 101

D.C.B. Whittet, P.A. Gerakines, A.G.G.M. Tielens, A.J. Adamson, A.C.A. Boogert, J.E. Chiar, T. de Graaw, P. Ehrenfreund, T. Prusti, W.A. Schutte, B. Vandenbussche, E.F. van Dishoek, 1998, ApJ. Lett., 498, L159

D.A. Williams, S.D. Taylor, 1996, Q.J.R.A.S., 37, 565

L.P. Wright, M.M. Grady, C.T. Pillinger, 1997, Lunar Planet. Sci., XXVIII, 1591

F. Rostas

President of the Commission 